Volume 65

Issue 1 Fall 2015: Twenty-Fifth Annual DePaul

Law Review Symposium - The UAS Dilemma:

Article 3

Unlimited Potential, Unresolved Concerns

\title{
Nudging the Public's Health: The Political Psychology of Public Health Law Intervention
}

Hosea H. Harvey

Follow this and additional works at: https://via.library.depaul.edu/law-review

Part of the Law Commons

\section{Recommended Citation}

Hosea H. Harvey, Nudging the Public's Health: The Political Psychology of Public Health Law Intervention, 65 DePaul L. Rev. (2016)

Available at: https://via.library.depaul.edu/law-review/vol65/iss1/3

This Article is brought to you for free and open access by the College of Law at Digital Commons@DePaul. It has been accepted for inclusion in DePaul Law Review by an authorized editor of Digital Commons@DePaul. For more information, please contact digitalservices@depaul.edu. 


\title{
NUDGING THE PUBLIC'S HEALTH: THE POLITICAL PSYCHOLOGY OF PUBLIC HEALTH LAW INTERVENTION
}

\author{
Hosea H. Harvey*
}

TABle of Contents

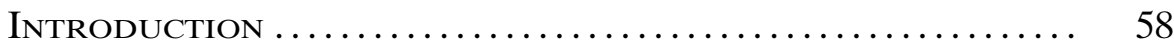

II. Toward a Political-Psychological Approach ... 63

III. Survey Data, Methodology, and Choice of Law

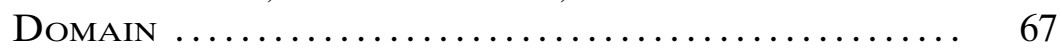

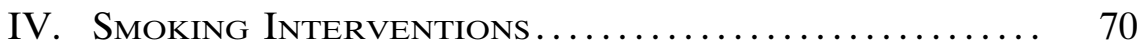

A. Theories of Smoking Interventions ............ 70

B. Smoking Intervention Trends............... 72

C. Smoking Interventions-Survey Questions and Results ...................................... 74

D. Conclusion-Smoking Interventions and Public Opinion .................................... 75

V. Food And Diet Interventions .................. 75

A. Theories of Food and Diet Interventions ......... 75

B. Food and Diet Intervention Trends............ 77

C. Food and Diet Interventions-Survey Questions and

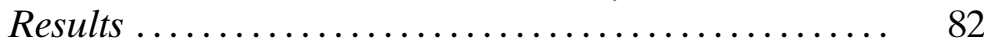

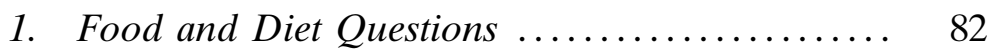

2. Calorie Count Question ................... 83

D. Conclusion-Food and Diet Interventions and Public Opinion ................................. 84

VI. Youth Sports TBI Laws-Assessing Support for Intervention By Messenger And Message ........ 85

A. Theories of Youth Sports Interventions.......... 85

B. Youth Sports Intervention Trends ........... 86

* J.D., Stanford Law School; Ph.D., Stanford University; Associate Professor of Law, Temple University, James E. Beasley School of Law. The author would like to thank Kathleen Bachynski, Jane Baron, Dorothy Brown, Scott Burris, Phil Garland, Heidi Grunwald, Dave Hoffman, Dionne Koller, Tom Lin, Jonathan Lipson, Kerri McGowan Lowrey, Greg Mandel, Frank McClellan, Michelle M. Mello, Stephanie Morain, Lauren Ouziel, Mark Rahdert and Rachel Rebouche, for their helpful comments as well as the generous faculty commenters at Villanova Law and Temple Law's faculty workshops. Rebecca Cole provided excellent research assistance as always. 
C. Youth Sports Interventions Experiment-The

Messenger................................

D. Youth Sports Interventions Experiment-The Message ................................ 91

E. Conclusions About Youth Sports Interventions ..... 93

VII. Sociodemographic Variance and Public Support FOR LAW InTERVENTION ........................ 93

A. Race and Interventions ..................... 93

B. Gender, Ideology, and Behavior-Identified Groups.. 95

C. Critiquing the Political-Psychological Approach .... 99

VIII. Conclusion ..................................... 100

Appendix ........................................ 103

\section{INTRODUCTION}

Until fairly recently, public opinion about the government's role in improving public health could be simply characterized. When a public health crisis arose, the public expected, even desired, that the government take some form of action. ${ }^{1}$ Increasingly, in recent decades, that government action took the form of new laws or regulations designed to achieve public health outcomes through coercion, compliance, or deterrence. But, in recent years, public health law interventions shifted toward "nudging" as a key method of inducing optimal public health behavior and achieving improved health outcomes. ${ }^{2}$ With this nudging came objections from scholars who argued that these interventions were simply going too far. ${ }^{3}$

Public opinion in favor of "old frontier" interventions was critical to determining when and how to mobilize legislatures to pass laws designed to address a given public health crisis. With respect to these traditional command and control law regimes, such as laws focused on drunk driving, research and evidence about public support for these laws was reasonably confined to focusing on support for law enactment. ${ }^{4}$ But, once these deterrent-centered laws were enacted, efforts

1. Wendy E. Parmet, Populations, Public Health, and the Law 1-2 (2009).

2. As defined by Thaler and Sunstein, a nudge "is any aspect of the choice architecture that alters people's behavior in a predictable way without forbidding any options or significantly changing their economic incentives." Richard H. Thaler \& Cass R. Sunstein, Nudge: Improving Decisions About Health, Wealth, and Happiness (2008). See also Cass R. SunStein, Simpler: The Future of Government 9 (2013); Richard H. Thaler, Misbehaving: The Making of Behavior Economics 232-25 (2015).

3. See, e.g., Lindsay F. Wiley et al., Who's Your Nanny? Choice, Paternalism and Public Health in the Age of Personal Responsibility, 41 J.L. MED. \& Eтhics 88, 90-91 (Supp. 2013) (challenging these objections).

4. For example, with respect to early research designed to explore methods to reduce instances and consequences of drunken driving, researchers identified that the public would need 
shifted toward focusing on enforcement as the primary tool to induce the desired behavior from the general public. Generally speaking, provided that the enforcement capacity was available and utilized, the public did not have to necessarily like the intervention for it to have the expected effect of reducing the targeted public health harm.

But, the new world of public health nudging is different. In addition to the importance of public support for the initial passing or implementation of nudge-style interventions, public support is critical post law enactment for the law to achieve maximum effectiveness. This effectiveness depends on continuing support for the law's objectives, especially if that support translates into action by individuals that alters behavior. Therefore, while public support for nudge-based interventions does not guarantee that the intervention will change behavior, it is a necessary ingredient. Thus, one additional reason to continuously evaluate public opinion about new public health interventions is that the public may need a sustained messaging campaign to maintain and build support for the intervention postenactment, and thus, ensure compliance over time absent a formal enforcement mechanism. In recent years, the scope and legitimacy of public health authority has been substantially questioned, and scholars have shaped influential responses to these critiques amidst some uncertainty about where public opinion presently stands. ${ }^{5}$ Some recent studies also suggest a wider-than-expected divergence of support for various public health law interventions challenging claims for broad public support. ${ }^{6}$ Therefore, this Article seeks to build on this scholarship by providing additional evidence about the scope and strength of public support for new-frontier public health law interventions.

To engage this debate, I gathered evidence about public support, norms, and behavioral change with respect to a series of recent public health law interventions. This evidence suggests that although these interventions receive widespread public support and shape public norms, public support and adoption of norms is highly contingent on membership in a subset of sociodemographic groups. But no matter

to be educated to support new laws, which would then serve as a necessary step toward future lawmaking efforts, allowing for an incremental increase in drunk-driving public health law interventions over time. See, e.g., David A. Sleet et al., Introduction: Drinking, Driving, and Health Promotion, 16 Health Educ. Q. 329 (1989).

5. See, e.g., Wendy E. Parmet, Beyond Paternalism: Rethinking the Limits of Public Health Law, 46 Conn. L. Rev. 1771 (2014); Lindsay F. Wiley, Sugary Drinks, Happy Meals, Social Norms, and the Law: The Normative Impact of Product Configuration Bans, 46 Conn. L. REv. 1877 (2014).

6. See, e.g., David Orentlicher, Controlling Health Care Costs Through Public, Transparent Processes: The Conflict Between the Morally Right and the Socially Feasible, 36 J. CoRP. L. 807, 813-17 (2011) (describing public response to a variety of contested interventions). 
the legal domain, "public opposition is a potential barrier to effective implementation" of any new law. ${ }^{7}$ And, with an increasing focus on challenging the legitimacy of public health lawmaking efforts, there is substantial value in identifying and reinforcing the consistency and saliency of "public health's democratic roots." 8 Therefore, it is useful to identify how empirical evidence about public support for these interventions should be incorporated into both public health lawmaking and public health law research.

But, while at the individual level the decision to adopt or embrace a public health law should obviously be salient and central to both the process of lawmaking and dissemination of the law's content, much more can be said about the application of public opinion and political psychology to this process. ${ }^{9}$ While policy optimization is important, moving from policy creation and implementation to the communication and persuasion required for individuals to adopt policy norms and modify behaviors and beliefs is equally worthy of the sustained scientific effort of public health law scholars and others engaged in this debate. ${ }^{10}$ As Professor Dan M. Kahan explains: "Neither the mechanisms for generating evidence-based risk communication nor the shared professional understandings necessary to enable its successful execution exist today." 11 Due to recent public health law inter-

7. Tho Bella Dinh-Zarr et al., Reviews of Evidence Regarding Interventions to Increase the Use of Safety Belts, 21 Am. J. Preventative Med. 48, 52 (Supp. 2011).

8. Lindsay F. Wiley et al., Adventures in Nannydom: Reclaiming Collective Action for the Public's Health, 43 J.L. Med. \& Ethics 73, 75 (Supp. 2015).

9. Thus, this Article builds on the recent work of Stephanie Morain \& Michelle M. Mello, Survey Finds Public Support for Legal Interventions Directed at Health Behavior To Fight Noncommunicable Disease, 32 HeAlth AfF. 486, 487 (2013), which describes the general absence of public opinion work with respect to public health law interventions and deploys a national survey designed to test the relationship between public perception of legitimacy and support for various interventions.

10. See Sungwoo Lim \& Tiffany G. Harris, Neighborhood Contributions to Racial and Ethnic Disparities in Obesity Among New York City Adults, 105 Ам. J. Pub. Health 159 (2015) (introducing a sophisticated data analysis of confounding policy-related variables linked to race and ethnic-obesity outcome disparities but without mention of public opinion, communication, and dissemination of these policies as mediating influences); see also Emma Elizabeth McGinty et al., Gun Policy and Serious Mental Illness: Priorities for Future Research and Policy, 65 PsycHIATRIC SERvs. 50, 56 (2014) (focusing on policy design but not messaging or communication); Jeffrey W. Swanson et al., Mental Illness and Reduction of Gun Violence and Suicide: Bringing Epidemiologic Research to Policy, 25 Annals of Epidemiology 366 (2015) (gathering and analyzing data from a variety of sources to create optimal policy for the reduction of gun violence). The scholarly rigor in these works centers on recommendations involving the nuances of how science and epidemiology can inform public health law creation but not on how public opinion or political psychology can be used to influence either communication or persuasion with respect to the same public health law interventions.

11. Dan M. Kahan, Vaccine Risk Perceptions and Ad Hoc Risk Communication: An Empirical Assessment, CCP Risk Perception Studies Report No. 17, at 10 (2014). 
ventions and regimes, we have ample evidence showing that (theory notwithstanding) poor communication can actually engender and exacerbate public opposition to these interventions. ${ }^{12}$

Public health law research has shown that some public health law interventions have: (1) enjoyed broad public support; (2) been easily adopted; and (3) positively impacted public health outcomes; on the other hand, some laws - and proposed laws-encounter significant resistance, and thus have a decreased impact on improving public health outcomes. ${ }^{13}$ But, because attention to innovation in public health law interventions has been increasing, not slowing, and because cities, states, and the federal government are passing more laws to protect the public health, now is an optimal time to consider how to best effectively communicate with and influence the public about modifying public health behaviors.

The survey-research results in this Article attempt to contribute toward reducing the theoretical noise and suggest new directions for future research centered in optimizing methods for both making and communicating public health law and policy. Many recent public health law interventions, absent significant coercion or criminal enforcement penalties, rely much more heavily on persuasion (the sell) than they do on traditional theories of criminal deterrence. ${ }^{14}$ To align research with real-world application, the public health law interventions analyzed in this Article, and the survey instrument discussed infra, by and large rely on a combination of education, nudges, and lessinvasive enforcement regimes to accomplish their goals. ${ }^{15}$ To improve the theoretical and empirical foundations for existing and future interventions, ${ }^{16}$ this Article gathers public opinion data from an original national survey sample of more than 2,000 adults in the United

12. E.g., Sarah E. Gollust et al., Controversy Undermines Support for State Mandates on the Human Papillomavirus Vaccine, 29 Health Aff. 2041, 2045 (2010).

13. E.g., Rebecca Haffajee et al., What Is a Public Health "Emergency"?, 371 N. ENG. J. Med. 986, 988 (2014) (cautioning that an expansive use of law for public health interventions, particularly those that are labeled public health emergencies, may cause the public to "lose trust in health officials, which may result in a loss of political legitimacy as well as a backlash against public health laws more generally").

14. See discussion infra Sections IV.B., V.B., and VI.B.

15. See Kerri McGowan Lowrey \& Stephanie R. Morain, State Experiences Implementing Youth Sports Concussion Laws: Challenges, Successes, and Lessons for Evaluating Impact, 42 J.L. MeD. \& Ethics 290, 297 (2014) (assessing implementation of youth sports TBI laws and finding enforcement of these laws is "largely nonexistent, due to the absence of such language in the laws and uncertainty about under whose purview enforcement falls").

16. E.g., Scott Burris et al., Legal Regulation of Health-Related Behavior: A Half-Century of Public Health Law Research, 9 AnN. Rev. L. Soc. Sci. 95, 96 (2013) ("There was little crossfertilization of methods .... Research on health laws has not been informed by theory and methods developed in sociolegal research.”). 
States. ${ }^{17}$ To resolve uncertainties about the impact of these new interventions when filtered through the lens of public opinion, the sample engages a variety of recent public health law domains (smoking, food and diet, and youth sports traumatic brain injuries (TBIs)). The study then asks several questions, including: (1) whether lawmaking in these domains is generally supported by the public; (2) if sociodemographic barriers impede the public's general acceptance and adoption of these laws; and (3) whether other variables, such as the nature of how these laws are communicated or the substance of the laws' education components, substantially impact or modify the public's decision to adopt the laws' norming principles. ${ }^{18}$ Throughout, the goal of the survey was to capture and compare attitudes about laws situated somewhere between more traditional quasi-deterrent regimes on the one hand (smoking and sports bans, for example), and information-based nudge regimes designed to either structure or influence individual choices and behaviors on the other (such as calorie counts and concussion education).

This Article unfolds in six parts. Part II builds on prior works and describes a political-psychological approach to understanding support for public health law interventions. ${ }^{19}$ Part III describes the survey methodology. ${ }^{20}$ Parts IV and V explore the recent history of two public health law domains and public support for interventions within those respective domains. ${ }^{21}$ Part VI builds on the previous two Parts by focusing on a newly salient domain, youth sports TBI laws, and applies two experimental methodologies to the framework: (1) testing the effect of differentiations on the public's response for the intervention to different authoritative support for the intervention; and (2) testing the effect of education and information on persuasion. ${ }^{22}$ Part VII explores sociodemographic variance in attitudes across all of these interventions and asks whether this variance has particular implications for future public health law interventions. ${ }^{23}$ The Article concludes with a call for further research. ${ }^{24}$

17. See infra Part III (explaining the original survey's methodology).

18. While focusing on sociodemographic differences and political psychology, this work is also influenced by the theory of planned behavior. See generally Icek Ajzen, The Theory of Planned Behavior, 50 Organizational Behav. \& Hum. Decision Processes 179 (1991).

19. See infra notes $25-44$ and accompanying text.

20. See infra notes $45-60$ and accompanying text.

21. See infra notes 61-132 and accompanying text.

22. See infra notes $133-57$ and accompanying text.

23. See infra notes 159-74 and accompanying text.

24. See infra notes $176-81$ and accompanying text. 


\section{Toward a Political-Psychological Approach}

Leaders in public health law research evaluated a range of legal effect theories across diverse fields to inform the methodology used in public health law research. ${ }^{25}$ A variety of literature and approaches attempt to tie the underlying theoretical perspective to the public's agreement to either adopt new legal norms or change existing behavior based on these laws' prescriptive or proscriptive content. For example, scholars led by professor Tom R. Tyler and colleagues pivot to the role of the state's legitimacy when enacting new legal regimes designed to coerce or influence behavior through a variety of methods. ${ }^{26}$ A newer strand of research, conducted by Dan M. Kahan and colleagues, focuses on a vector of values, which for a given subset of law interventions, may serve as an important predictor of opinion or constraint on individual behavior. Through an interest in broadening their audience to include public health researchers and policy advocates, Tyler, Kahan, and others have directly engaged their work to new issues in public health. ${ }^{27}$ Still, other theorists posit a cost-benefit framework for behavior modification and law adoption at the individual level, rooted in classical economic perspectives centered on the nexus between the cost of achieving the law's desired behavioral modification and the cost-benefit of noncompliance. ${ }^{28}$ Taxation as a method of public health strategy remains front and center in national discourse. ${ }^{29}$ In addition, a variety of important ethical concerns with both past and present public health policies and interventions inform debates about the costs and benefits of these interventions. ${ }^{30}$ These perspectives add broad value to the field of public health law research,

25. See Public Health Law Research: Theory and Methods passim (Alexander C. Wagenaar \& Scott C. Burris eds., 2013) (ebook) [hereinafter Public Health Law REASEARCH].

26. Tom R. Tyler, Why People Obey the Law 71 (1990); see Paul H. Robinson, Distributive Principles of Criminal Law: Who Should Be Punished How Much? (2008) (explaining that it is necessary for authorities to articulate distributive principles to maintain legitimacy); Paul H. Robinson \& John M. Darley, Justice, Liability and Blame: CommuNity Views and the Criminal Law 7 (1995).

27. See, e.g., Kahan, supra note 11, at 13-18; Tom R. Tyler \& Avital Mentovich, Procedural Justice Theory, in Public Health Law Research, supra note 25, at 247-48.

28. Public Health Law Research, supra note 25, at 202.

29. Michelle M. Mello \& I. Glenn Cohen, The Taxing Power and the Public's Health, 367 NEw ENG. J. Med. 1777, 1779 (2012); see also Alexander C. Wagenaar, Melvin D. Livingston, and Stephanie S. Staras, Effects of a 2009 Illinois Alcohol Tax Increase on Fatal Motor Vehicle Crashes, 105 Ам. J. Pub. Health 1880 (September 2015) (describing public health effects of an alcohol tax on alcohol-related fatalities in Illinois).

30. See, e.g., Michele Goodwin \& Allison M. Whelan, Law, Bioethics, and Biotechnology, in 13 International Encyclopedia of the Social \& Behavioral Sciences (James D. Wright ed., 2d ed.) (forthcoming 2015). 
but none are squarely centered on the role of public opinion as applied to nudge-based public health law interventions. To provide an alternative (or supplement) to these research regimes, this Article engages political science and political psychology frameworks to explore the connection between nudge-based interventions, public opinion, and public health outcomes.

Thus, this Article builds on the aforementioned scholarly traditions but suggests that we can learn a lot about recent interventions by applying a political psychology framework. In such a framework, political-psychological processes related to sociodemographic group membership are the primary drivers of individual preferences, attitudes, and behaviors with respect to law interventions. For example, some public health law interventions threaten individual interests (e.g. antismoking laws for smokers) and should in turn reduce public support among the most self-interested groups across particular public health domains. ${ }^{31}$ And, because ideological strength can drive individual rejection of new laws, it is expected that conservative members of the public will reject public health law interventions at higher rates than moderate and liberal members. Race and other sociodemographic variables are signals of certain cultural, political, and psychological norms rooted in an individual's group membership, and will serve as psychological and political filters at the individual level, influencing both support for these laws as well as compliance with the intended behavioral nudges these laws seek to create. ${ }^{32}$

Political psychology theorists assume that one's sociodemographics are not genetically determinative of one's policy views, but instead, cause an individual to encounter distinct experiences over time, which then inform these views. ${ }^{33}$ As one scholar explains: "[African-Americans] may not think or act any differently than whites because of their

31. This phenomenon is somewhat consistent with a theory of cognitive dissonance avoidance or what Kahan and others now refer to as identity-protective cognition. Dan M. Kahan et al., Culture and Identity-Protective Cognition: Explaining the White-Male Effect in Risk Perception, 4 J. Empirical Legal Stud. 465, 469-70 (2007). Thus, it would be reasonable that one's identity as a smoker would prevent support of antismoking laws.

32. But, while the author might expect to find that a particular ethnic group is more likely to support a given intervention, it would be wrong to suggest that membership in the minority group is causally related to supporting the intervention. Nonetheless, as shall be discussed in Part VII, if it is true that group membership, standing alone, is correlated with stronger or weaker support, this correlation can still be utilized to develop communication and dissemination strategies that capitalize on group-based differences regardless of the underlying cause. See infra notes 159-74 and accompanying text.

33. See Generally, Donald R. Kinder and Allison Dale-Riddle, The End of Race?: Obama, 2008, And Racial Politics in America (2012). Within law scholarship, those who study critical race theory also share this view. See, e.g., Dorothy A. Brown, Fighting Racism in the TwentyFirst Century, 61 WASH. \& LEE L. REv. 1485, 1491 (2004) (explaining that one central tenant of 
genetic endowment, but they grow up with a different set of experiences and those different experiences give them qualities that other people lack." 34 For example, political psychology and public opinion studies throughout the last several decades show that despite ample history living through an array of discriminatory legal regimes, African-Americans (and to a lesser extent other ethnic minorities) continue to possess a higher degree of support for a variety of government policies than white survey respondents. Yet, as a variety of scholars have amply demonstrated, this high level of support coexists with a history of formalized inequity and discrimination, especially with respect to healthcare and public health policies throughout much of American history. ${ }^{35}$ Though there are ample historical reasons for African-Americans to mistrust mainstream medical and health establishments, ${ }^{36}$ as well as well-established nonprofit public health regimes, ${ }^{37}$ it is expected that the group's consistent and recent confidence in government institutions and policies will be a more significant determinant of support for public health interventions than any competing or conflicting opinions about historic and present day legal and medical inequities. ${ }^{38}$ Thus, it is expected that with respect to the public health interventions described in this Article, ethnic-minority respondent support will be, on average, higher than support from white respondents.

During the past several decades, public opinion surveys have also shown that women support a wide variety of government policies

critical race theory is that "to be a person of color in America is to be subject to racial subordination").

34. David Orentlicher, Diversity: A Fundamental American Principle, 70 Mo. L. Rev. 777, 808 (2005).

35. See, e.g., Taunya Lovell Banks, Funding Race as Biology: The Relevance of "Race" in Medical Research, 12 MinN. J.L. SCI. \& TECH. 571, 575-77 (2011) (examining the use of race in biomedical research); Kevin Outterson, Tragedy and Remedy: Reparations for Disparities in Black Health, 9 DePaul J. Health Care L. 735, 747 (2005) ("The history of Black health in America is cruel and shocking.").

36. See Inst. of Med., Unequal Treatment: Confronting Racial and Ethnic Disparities in Health Care 30 (Brian D. Smedley et al. eds., 2003); see also Michele Goodwin \& Nevin Gewertz, Rethinking Colorblind State Action: A Thought Experiment on Racial Preferences, Law \& Contemp. Probs., Fall 2009, at 251, 262-64.

37. See Kara W. Swanson, Banking on the Body: the Market in Blood, Milk, and Sperm in Modern America 63-65, 72, 79 (2014) (describing the legacy of racial coding and discrimination within the blood bank history).

38. Robert Gatter, Faith, Confidence, and Health Care: Fostering Trust in Medicine Through Law, 39 WAKe Forest L. Rev. 395, 430-33 (2004) (reviewing studies that evaluate the historical connection between patient ethnicity and trust of doctors and suggesting that public health gains and support from these groups would be better realized by the deemphasis of trust in doctors in favor of building confidence in medicine). 
more so than men. ${ }^{39}$ Thus, it is expected that similar to these prior samples, women will support public health law interventions at greater rates than men. I predicted that this support would be higher than corresponding male support for nudge-based interventions notwithstanding that other recent deterrent public health interventions specifically focused on women have proven to be politically divisive..$^{40}$ Further, ample evidence suggests that women may have a variety of reasons to mistrust doctors and healthcare systems, and by extension, health-related interventions. ${ }^{41}$ Nevertheless, it is posited that the political attitudes of women respondents, who have higher levels of overall support for government policies, will override any present day mistrust of medicine or the government's role in regulating healthcare policies for women.

Finally, a variety of studies have shown that priming the survey respondent with a trusted, respected, or ideological opponent (messenger or advocate) of a particular policy can trigger an increased politically supportive or aversive response to the policy. ${ }^{42}$ Most recently, University of Chicago Postdoctoral Research Fellow, David Tannenbaum, and his colleagues found evidence of a nudge bias, which prompted respondents to object to nudges when they were applied to policy objectives or policymakers they opposed. ${ }^{43}$ Similarly, respondents found the same nudges more acceptable when they were applied to political objectives or policy makers they supported. ${ }^{44}$ Thus, the survey in this Article contains an experiment varying the policy supporter and changing the reasoning for the policy objective to further determine whether sociodemographic group membership and political ideology influence public support for public health law interventions.

39. See, e.g., Ctr. for the American Woman \& Politics, the Gender Gap: Attitudes on Public Policy Issues (2012), http://www.cawp.rutgers.edu/sites/default/files/resources/ gg_issuesattitudes-2012.pdf.

40. See R. Alta Charo, Physicians and the (Woman's) Body Politic, 370 N. Eng. J. Med. 193, 193-94 (2014) (describing political and legal conflicts between medicine, science, and recent legislative efforts to regulate various aspects of pregnancy, including the provision of scientifically contested information to protect the public health).

41. Diane E. Hoffmann \& Anita J. Tarzian, The Girl Who Cried Pain: A Bias Against Women in the Treatment of Pain, 29 J.L. MED. \& ETHICs 13, 13 (2001) ("[W]omen are more likely to seek treatment . . . but are also more likely to be inadequately treated by health-care providers.").

42. See generally Dan M. Kahan et al., Cultural Cognition of Scientific Consensus, 14 J. Risk REs. 147 (2011).

43. David Tannenbaum et al., On the Misplaced Politics of Behavioral Policy Interventions 4 (Working Paper), http://scholar.harvard.edu/todd_rogers/publications/misplaced-politics-behavioral-policy-interventions.

44. Id. at 7. 


\section{Survey Data, Methodology, and Choice of Law Domains}

I designed a thirty-four question survey instrument with structured response categories to elicit public opinion on the three public health intervention policy domains discussed in this Article (smoking, food and diet, and youth sports TBI laws) and to test within the survey's randomized design: (1) the messenger of the law's efficacy, such as doctors, political figures, public health advocates; and (2) the role of additional information in changing the likelihood of public support for the law. To achieve facial and content validity, I developed the survey questionnaire in consultation with public health law researchers, legal academics, content experts, and methodology advisors at SurveyMonkey-a professional survey organization. Internal SurveyMonkey experts evaluated the draft survey, and a brief simulated pilot was run on a small online panel to test for comprehension and functionality prior to revision of the survey instrument. 45

Each of the three aforementioned intervention areas was chosen for several key reasons. First, smoking builds on decades of existing law and messaging, and if time and messaging, standing alone, influence opinion and behavior, smoking interventions should be the most supported of the group. The other two interventions ((1) food and diet and (2) youth sports TBI laws) represent the "new frontier" of public health law interventions: those that are most likely to encounter public resistance, and thus, are particularly important for evaluation. ${ }^{46}$ Second, these interventions were chosen because of their potential public health impact. ${ }^{47}$ For example, tobacco use and poor diet and exercise accounts for almost $35 \%$ of deaths in the United States. 48 Thus, at their core, public health law interventions designed to increase either physical activity or improve diets should have a logic model for the likelihood of individual support and adoption of the law's substance and behavior modification goals. ${ }^{49}$ The remaining

45. Further details about the design and methodology are in the Appendix. See infra notes 184-86, and accompanying text.

46. See Morain \& Mello, supra note 9, at 486-87 (identifying these issues as distinct from other more traditional public health law interventions).

47. See, e.g., Ali H. Mokdad et al., Actual Causes of Death in the United States, 2000, $291 \mathrm{~J}$. Aм. Med. Assoc. 1238, 1238-39 (2004) (explaining in part that more intractable problems, such as obesity, have greater long-term public health consequences than other more direct causes of harm or death, such as communicable diseases).

48. Id. at 1238 .

49. See, e.g., Michelle M. Mello et al., Obesity-The New Frontier of Public Health Law, 354 N. Eng. J. Med. 2601, 2602-04 (2006) (providing examples of approaches to obesity in public health law); see also William H. Dietz \& Alicia S. Hunter, Legal Preparedness for Obesity Prevention and Control: The Public Health Framework for Action, 37 J.L. MED. \& ETHICs 9, 10-11 
parts of this Article attempt to provide evidence to assist in future research about the intersection of public opinion, new-frontier interventions, and long-term goals of improving public health.

Because this approach seeks to add to a nascent dialogue, it is necessarily limited in scope. Subsequent work with the data gathered for this Article unpacks some field-specific inquiries and explores the survey results utilizing additional questions not reported here, multi-variate methods, and terminology intended for a more specialized healthscience audience. It is expected that future work might explore additional ways that law intersects with public health, ranging from responses to state or local emergencies, ${ }^{50}$ coordinated legal responses to pandemics, ${ }^{51}$ state level restrictions on doctor-patient speech, ${ }^{52}$ social controls,,$^{53}$ and the use of legally mandated or industry developed technology initiatives to improve either healthcare management or patient-health awareness. ${ }^{54}$ Future research might bridge a variety of the aforementioned areas and further explain why some interventions achieve broad support while others encounter significant resistance. This research should identify the factors that influence public support for the law or speed the adoption of the desired behavior. Experimental survey design can help observers further understand the value in changing both the messenger and the message. This research can then be utilized to both better sell existing interventions and become part of the evidence in evidence-based policy making prior to law enactment and implementation. But, at least initially, this research focuses on a discrete set of interventions with much substance in common to provide a useful framework for further exploration of the aforementioned additional areas.

(2009) (describing wide-ranging efforts to use public health law and regulation to reduce obesity while acknowledging that the research design for how these interventions can be successfully deployed is still in its nascent stages).

50. See generally Elizabeth A. Weeks, Lessons from Katrina: Response, Recovery, \& the Public Health Infrastructure, 10 DePaul J. HeAlth CARE L. 251, 256-67 (2007) (explaining the challenges health care providers face in responding to a natural emergency).

51. Nan D. Hunter, "Public-Private” Health Law: Multiple Directions in Public Health, $10 \mathrm{~J}$. Health Care L. \& Pol'y 89, 89-90 (2006); Wendy E. Parmet, Pandemics, Populism and the Role of Law in the H1N1 Vaccine Campaign, 4 ST. Louis U. J. Health L. \& Pol'y 113, 113-14 (2010).

52. See David Orentlicher, Abortion and Compelled Physician Speech, 43 J.L. Med. \& ETHICS 9, 9-10 (2015).

53. Wendy Parmet, Public Health \& Social Controls: Implications for Human Rights 11 (Northeastern Pub. Law \& Theory Faculty Working Papers Series, No. 44-2010, 2010), http:// papers.ssrn.com/sol3/papers.cfm?abstract_id=1546654.

54. Nicolas P. Terry, Information Technology's Failure to Disrupt Healthcare, 13 NEV. L.J. 722 (2013) (charting the course of health information technology history and positing trends for the future). 
The following Parts proceed as follows. In Parts IV and V, the theoretical models for public health intervention with respect to smoking and food and diet will be situated against the development of recent public health law interventions at the federal, state, and local levels. ${ }^{55}$ Viewing these domains separately, public opinion about interventions in both domains will be examined to determine whether: (1) the public generally supports the interventions; and (2) substantial sociodemographic differences manifest in this support. Part VI situates the theoretical model for intervention with respect to youth sports concussions against the development of recent state laws designed, in part, to minimize some instances of these injuries. ${ }^{56}$ But, rather than gauge general public support for these interventions, Part VI pivots to an experiment within the survey experiment designed to determine if the quality, ideology, or familiarity of the messenger, ${ }^{57}$ or the education component or tone of the message, influences public opinion about the law intervention. ${ }^{58}$ Part VII discusses the experiment's results and then turns toward a broader discussion about sociodemographic stratification within the results in Parts IV-V and the implications for future public health law intervention. ${ }^{59}$

Reflecting on the abovementioned research and literature, I expected to find that the general public supports a variety of public health law interventions by substantial margins. Further, even when these interventions intrude on individual autonomy or provide information and education that heightens awareness of an individual's nonconformity to public health ideals-such as an average daily caloric intake that diverges substantially from a norm-the general public will still respond favorably to these interventions. ${ }^{60}$ Further, although

55. See infra notes 61-132 and accompanying text.

56. See infra notes $133-57$ and accompanying text.

57. See Elizabeth Weeks Leonard, Death Panels and the Rhetoric of Rationing, 13 NEv. L.J. 872,873 (2013) (providing an anecdote of the role that key public figures played in messaging and influencing public opinion about various provisions in the Affordable Care Act).

58. See infra notes 133-57 and accompanying text; Wiley et al., supra note 3, at 88-89 (describing the negative effects of messaging these intervention efforts as being part of the "nanny state"). In a version of the approach taken by Kahan and colleagues, the name or title of the expert is simply given while the message remains constant to make the test more salient based on name or affiliation standing alone. Dan Kahan et al., Who Fears the HPV Vaccine, Who Doesn't, and Why? An Experimental Study of the Mechanisms of Cultural Cognition, 34 L. Hum. Behav. 501 (2010).

59. See infra notes $159-74$ and accompanying text.

60. Morain \& Mello, supra note 9, at 490. Morain and Mello's recent work suggests, as do the data gathered for this Article, that general support for a wide variety of new-frontier public health law interventions exceeds $70 \%$ support for even the most invasive interventions and moves into near unanimity $(88.9 \%)$ for others. $I d$. Only truly coercive hypothesized regimes (in other words, ones that have never been credibly proposed by regulators or legislators) received 
there is not substantial prior research explicitly focused on linking individual sociodemographic variables with support of law in these domains, I expected that marginalized ethnic groups and women will be more supportive of public health law interventions than the general public.

\section{SMOKING InTERVENTIONS}

\section{A. Theories of Smoking Interventions}

Smoking interventions represented a response to a sociocultural shift in attitudes toward the act of smoking itself. ${ }^{61}$ Whereas food and diet related public health interventions seek to reduce health care costs overall as a function of reducing poor food choices, smoking interventions were first positioned as the government helping individuals protect themselves and their families from others' harmful behaviors that negatively impacted their health. ${ }^{62}$ Initial public health interventions relating to smoking started, as many such interventions do, at the local level. ${ }^{63}$ Local experimentation with law intervention, along with vigorous advocacy and a national dialogue about smoking, resulted in a variety of interventions ranging from clean air rules to advertising restrictions. ${ }^{64}$

As national awareness of the health risks regarding firsthand and secondhand smoke reaches an all-time high, "old" public health law interventions with respect to smoking are no longer controversial and

weak support. $I d$. Thus, while Morain and Mello find substantial opposition to public health law interventions which "make possession of soda and other junk foods a disciplinary offense" in public schools or "permit employers to test and fire for tobacco use," the absence of a public proposal to do this or even a public dialogue would naturally lead to intense public opposition if respondents were hearing it for the first time. Id.

61. See, e.g., Raymond Leung et al., Instituting a Smoke-Free Policy for City Recreation Centers and Playgrounds, Philadelphia, Pennsylvania, 2010, 10 Preventing Chronic Disease E116 (July 11, 2013), http:/www.cdc.gov/pcd/issues/2013/pdf/12_0294.pdf (discussing efforts to ban smoking in public spaces in Philadelphia and noting, "[k]ey areas of evidence in support of our policy included ... supporting a normative message that smoking is harmful, [and] motivating smokers to quit" among others).

62. The first smoking interventions that provided for outright prohibitions were often located in local health-centered establishments. See Diane M. Becker et al., The Impact of a Total Ban on Smoking in the Johns Hopkins Children's Center, 262 J. Aм. MED. Assoc. 799, 799-800 (1989) (detailing and discussing a ban on smoking in a hospital); John P. Mullooly et al., Smoking Behavior and Attitudes of Employees of a Large HMO Before and After a Work Site Ban on Cigarette Smoking, 105 Pub. HeAlth Rep. 623, 623 (1990) (HMO ban).

63. Kathleen Hoke Dachille, Using Law To Improve Public Health: The Example of Tobacco Regulation, 17 NYSBA HeAlth L.J. 32, 32 (2012).

64. Id. at $32-33$. 
are widely accepted. ${ }^{65}$ Therefore, public health advocates shifted within this policy domain, calling for new and innovative measures designed to further reduce the harm caused by direct and indirect consumption of smoke. ${ }^{66}$ The arguments for protecting children from secondhand smoke carry particular weight with the public because children are viewed separately from the adult free-market sphere of behavioral health choices. ${ }^{67}$ New smoking interventions rely less on formal enforcement regimes and more on compliance by persuasion. But, "no systematic literature exists on the number of fines that have been imposed in the many locales that have enacted [public smoking] bans[,]"68 rendering it difficult to determine if these regimes are generally effective. On the other hand, attempts to limit smoking in private spaces have received much pushback from critics and smokers who view the efforts as overreaching governmental intrusion.

Building on prior limited interventions, lawmakers developed new interventions focused not on educating the individual smoker, but instead, on creating outright prohibitions and economic incentives to reduce the harm from smoking-writ large. Some interventions take the form of outright smoking bans across cities and states. Smoking bans operate as a prohibition first and foremost. ${ }^{69}$ These are the antinudges. Yet a secondary effect of these prohibitions may also increase awareness about the health hazards of the forbidden behavior, which is a form of nudging nevertheless. Lawmakers hope that through increased awareness, the general public will adopt the principal message - that smoking is an unhealthy behavior - and that they will act on it by not smoking. ${ }^{70}$ The ultimate goal of smoking bans is twofold

65. Patrick Kabat, Note, "Till Naught but Ash Is Left To See”: Statewide Smoking Bans, Ballot Initiatives, and the Public Sphere, 9 Yale J. Health Pol'y L. \& Ethics 128, 130-31 (2009) (outlining the developments in smoking legislation but cautioning that the shift in laws from permissive to prohibitive should develop responsibly).

66. See, e.g., Jonathon P. Winickoff et al., Regulation of Smoking in Public Housing, 362 N. ENG. J. MED. 2319, 2319, 2322 (2010) (outlining the potential policy reasons for having the U.S. Department of Housing and Urban Development ban smoking in public housing).

67. Leung, et al., supra note 61 ("[S]moke-free policies support a normative message that smoking is unsafe and that nonsmokers have the right to be protected. This is especially significant for children because children are influenced by their perceptions of normal behavior.").

68. Ronald Bayer \& Kathleen E. Bachynski, Banning Smoking in Parks and on Beaches: Science, Policy, and the Politics of Denormalization, 32 Health Aff. 1291, 1297 (2013).

69. See Fabrizio Turoldo, Responsibility as an Ethical Framework for Public Health Interventions, 99 Ам. J. Pub. Health 1197, 1198 (2009).

70. N.Y.C. Dep't of Health \& Mental Hygiene, Smoke-Free Workplace Legislation Will Save Lives-and It Won't Hurt Business 5, http://www.nyc.gov/html/doh/downloads/ pdf/smoke/sfaa-brief-book.pdf (last visited July 9, 2015) ("Smoke-free workplace legislation also reduces the social acceptability of smoking, and therefore helps reduce smoking in general."); Leung, et al., supra note 61. See N.Y.C. Dep’t of Health \& Mental Hygiene, Executive SummARY, http://www.nyc.gov/html/doh/downloads/pdf/smoke/shsmoke.pdf (last revised June 
in this sense: (1) prohibit a certain behavior in a given context; ${ }^{71}$ and (2) prevent or eliminate that behavior overall. Indeed, smoking bans have decreased individual smokers' opportunities to smoke in many settings, and therefore reduced their volume of smoking or inspired them to quit or attempt to quit. ${ }^{72}$ Increased cigarette costs through taxation have had similar effects. ${ }^{73}$ Overall, recent public health law interventions regarding smoking seem inextricably linked to more modern interventions with respect to both food and diet and youth sports TBI laws because one key method of legal effect uniting them is an effort to achieve compliance with the law's goals without a significant deterrent or compliance regime standing behind it. ${ }^{74}$

\section{B. Smoking Intervention Trends}

Despite the abovementioned effects, new smoking-related public health interventions have been some of the most contentious regulations and laws across the country. ${ }^{75}$ Developing awareness about the health hazards of smoking and secondhand smoke caused public health advocates to propose bans on smoking in public places, regulations prohibiting smoking in and around certain workplaces, and suggesting smoking bans in some private places, such as in cars with children. ${ }^{76}$ Several states banned workplace smoking statewide, in-

10,2008 ) (" $10 \%$ to $20 \%$ of smokers would quit if smoking were prohibited in their workplace. Even among those who continue to smoke, average consumption would decrease by $6 \%$.").

71. The targeting of behavior, of course, triggers different self-interest mechanisms for interventions like antismoking initiatives when the behavior is directly aligned with self-interest and personal identity. Morain \& Mello, supra note 9, at 493.

72. See Rong W. Zablocki et. al., Smoking Ban Policies and Their Influence on Smoking Behaviors Among Current California Smokers: A Population-Based Study, Prev. Med. 73 (2014).

73. See Frank J. Chaloupka et al., Tobacco Taxes as a Tobacco Control Strategy, 21 ToвACCO Control 172, 179 (2012).

74. See, e.g., Robert A. Kagan \& Jerome Skolnick, Banning Smoking: Compliance Without Enforcement, in Smoking Policy: Law, Politics And Culture 69 (Robert Rabin \& Stephen Sugarman eds., 1993).

75. See Joe Palazzolo, Appeals Court Rejects Challenge to Outdoor Smoking Ban, Wall St. J.: L. BloG (Nov. 8, 2012, 1:06 PM), http://blogs.wsj.com/law/2012/11/08/appeals-court-rejects-challenge-to-outdoor-smoking-ban/. But see Rebecca Riffkin, Americans Favor Ban on Smoking in Public, but Not Total Ban: Nineteen Percent Favor Making Smoking Totally Illegal in U.S., GALLuP (July 30, 2014), http://www.gallup.com/poll/174203/americans-favor-ban-smoking-public-nottotal-ban.aspx (last visited February 1, 2015) (discussing the fact that the majority of Americans are in favor of making smoking in public illegal-something that the majority opposed until 2008).

76. Ctr. for Disease Control and Prevention, Smoke-Free Policies Improve HeAlth, http:/www.cdc.gov/tobacco/data_statistics/fact_sheets/secondhand_smoke/protection/ improve_health/ (last updated May 12, 2014); Am. Nonsmokers' Rights Found. Overview List-How Many SMokefree Laws? (July 1, 2015), http://www.no-smoke.org/pdf/mediaordlist .pdf. But see Mark J. Horvick, Note, Examining the Underlying Purposes of Municipal and Statewide Smoking Bans, 80 IND. L.J. 923, 924 (2005) (acknowledging the increasing incidence of 
cluding California ${ }^{77}$ and North Dakota. ${ }^{78}$ Within the past decade, most of the sixty largest United States cities banned smoking in all restaurants and bars. ${ }^{79}$

A variety of private actors also created bans in the workplace..$^{80}$ But, despite many workplaces also banning smoking, exemptions for adult-only establishments or private clubs, casinos, and small workplaces have prompted litigation and dissent. ${ }^{81}$ As a result, it is unclear whether the public supports these new laws designed to prohibit individual behaviors, and if so, how best to frame these laws and their goals. ${ }^{82}$ Though a few studies have explored the public's support for

smoking bans, discussing the motivations for these bans, but criticizing smoking bans as going too far beyond protecting the only class of individuals who need governmental protectionchildren).

77. CAl. LABOr Code, $§ 6404.5$ (West 2003); Horvick, supra note 76, at 925 (characterizing California as having "started the fire" for smoking bans).

78. N.D. Cent. Code, § 23-12-10 (2012).

79. Paul A. Diller, The City and the Private Right of Action, 64 Stan. L. Rev. 1109, 1110, 1136-37 (2012) (discussing city smoking bans in the context of municipal policy choices); Paul A. Diller, Why Do Cities Innovate in Public Health? Implications of Scale and Structure, 91 WAsH. U. L. REv. 1219, 1225-36 (2014) (highlighting cities' leadership in smoking-related public health law interventions); Am. Nonsmokers' Rights Found., States, Commonwealths, and TerRitories With 100\% Smokefree Laws in all Non-Hospitality Workplaces, RestauRANTS, AND BARs, http://no-smoke.org/pdf/WRBLawsMap.pdf (last updated July 1, 2015) (describing broad trends for nonhospitality workplaces, restaurants, and bars); Anti-smoking Laws Spreading in Large Cities, Снart (Nov. 15, 2012, 12:01 PM), http://thechart.blogs.cnn.com/ 2012/11/15/anti-smoking-laws-spreading-in-large-cities/.

80. Leslie Zellers \& Samantha K. Graff, Workplace Smoking: Options for Employees and Legal Risks for Employers, ToBacco Control Legal Consortium, Apr. 2008, at 1, 3, http:// ucanr.edu/sites/tobaccofree/files/175147.pdf. See generally M. Todd Henderson, The Nanny Corporation, 76 U. CHI. L. REv. 1517, 1518-19 (2009) (discussing how and why corporations may regulate individual behaviors, including smoking and overeating, and analogizing these "nannyisms" to government regulation).

81. E.g., Office of Senate Floor Analyses, Bill Analysis, SB 575, 3d Sess., at 5 (Cal. 2011), http://www.leginfo.ca.gov/pub/11-12/bill/sen/sb_0551-0600/sb_575_cfa_20110601_124635_sen_

floor.html (supporting an amendment to legislation on smoking in the workplace, concluding that there is no safe level of exposure to secondhand smoke and emphasizing that workplace exposure disproportionately impacts low-income workers, young adults, and Latinos); Robert P. Hagan, Comment, Restaurants, Bars and Workplaces, Lend Me Your Air: Smokefree Laws as Private Property Exactions-The Undiscovered Country for Nollan and Dolan?, 22 J. ConTEMP. Health L. \& Pol'y 143, 146-47 (2005) (criticizing the application of smoking bans to private property); Steve Green, Judge Dismisses Second-Hand Smoke Lawsuit Against Caesars Entertainment, VEGAS INC (July 17, 2012, 2:00 AM), http://www.vegasinc.com/business/legal/2012/ jul/17/judge-dismisses-second-hand-smoke-lawsuit-against-/; Casino Employee in NJ Wins Cancer Suit for Second-Hand Smoke Forecasting a New Wave in Litigation, Gelmans (Feb. 20, 2008, 9:34 AM), http://www.gelmans.com/ReadingRoom/tabid/65/ctl/ArticleView/mid/372/articleId/76/ Casino-Employee-in-NJ-Wins-Cancer-Suit-for-Second-Hand-Smoke-Forecasting-a-New-Wavein-Litigation.aspx; Lung Cancer Victim Settles With A.C. Casino for $\$ 4.5 M$, NBC 10 PHILA. (Dec. 3, 2010, 5:22 PM), http://www.nbcphiladelphia.com/news/local/Lung-Cancer-Victim-SettlesWith-Casino-for-45M-111272304.html.

82. See Horvick, supra note 76, at 931 (criticizing smoking bans as tyrannical paternalism). But see Marot Williamson, Comment, When One Person's Habit Becomes Everyone's Problem: 
smoking restrictions ${ }^{83}$ none have done so across multiple domains or within the time frame most salient for recent public health law and policy interventions. Therefore, the survey discussed in this Article engaged two proposed smoking-centered public health law innovations to gauge overall public support and serve as empirical baselines for studying the nudge-based interventions discussed in the following Parts.

\section{Smoking Interventions-Survey Questions and Results}

The survey presented respondents with two questions about proposed public health law interventions with respect to smoking rooted in a series of recently proposed or enacted interventions. The questions were framed to explicitly raise the messenger's (the government) awareness of these laws as well as the political choice set presented by adoption of these laws, which both explicitly make clear that the proposed intervention will restrict individual choice in public and private spaces to benefit either the general public or children.

Questions:

1. Recently, New York City enacted a law designed to eliminate smoking in most public places, including parks, playgrounds, beaches and large open pedestrian plazas like Times Square. If such a new law were proposed where you live, how would you describe your level of support?

2. Recently, some have called for new laws to protect children against secondhand smoke. If your state was considering a mandatory law banning drivers and passengers from smoking in cars where children under 18 are passengers, how would you describe your level of support?

Responses were coded on a Likert scale from 1: strongly support the law to 7: strongly oppose the law. Mean responses for both proposals (city ban: 2.47 (se .046) and car ban: 2.17 (se .041)) were substantially in favor of the proposed interventions, suggesting generally strong

The Battle over Smoking Bans in Bars and Restaurants, 14 Vill. SpORTs \& ENT. L.J. 161, 176, 185-86 (2007) (praising smoking bans in private bars and clubs as attracting new customers and highlighting the ultimate economic benefits in health care costs).

83. See, e.g., Jennifer M. Doucet et al., Demographic Differences in Support for Smoking Policy Interventions, 32 Addictive Behav. 148, 150 (2007); Mary Kay Rayens et al., Public Support for Smoke-Free Laws in Rural Communities, 34 Am. J. Prev. Med. 519 (2008); George Thompson \& Nick Wilson, Public Attitudes to Laws for Smoke-Free Private Vehicles: A Brief Review, 18 Tobacco Control 256 (2009). 
public support for each of them, perhaps even stronger than previously realized by advocates for further interventions in this space.

\section{Conclusion-Smoking Interventions and Public Opinion}

Support for the interventions described above was fairly strong despite the somewhat invasive nature of the interventions. Thus, this support provides further evidence that: (1) coercive and deterrent regimes still remain generally popular; (2) there is large-scale political will for further interventions in this policy space; and (3) further research is needed to determine whether interventions that target children within a particular policy space are viewed more favorably than those that do not. These baseline numbers provide a useful control for evaluating public opinion about more recent new frontier interventions to which this Article now turns.

\section{Food And Diet Interventions}

\section{A. Theories of Food and Diet Interventions}

Although food and diet have long been discussed within the publichealth community with respect to their contributions to a growing obesity epidemic, these discussions did not focus on applying legal interventions to solve the problem. ${ }^{84}$ Most law-based interventions in this domain are of fairly modern vintage and have been restricted to two broad approaches: (1) the legal prohibition of certain types of food and drink, either generally or for specific populations; and (2) an attempt to modify behavior through legally mandated educationsuch as requirements for restaurants to list calorie counts next to food items. ${ }^{85}$ The first type of prohibition is neither a deterrent nor a coercion, yet modifies behavior by eliminating certain choices. The second intervention, a nudge, focuses on calorie counts and attempts to impact individual behaviors by raising awareness about the existence of calorie counts on restaurant menus and in other food retail contexts by making choice sets more salient. ${ }^{86}$ The calorie count requirements

84. See, e.g., Lester Breslow, Public Health Aspects of Weight Control, 42 Ам. J. Puв. Неalth 1116, 1119 (1952) (describing two suggested approaches to the public health problem of weight control).

85. See generally David Adam Friedman, Public Health Regulation and the Limits of Paternalism, 46 CONN. L. REv. 1687 (2014) (questioning whether nudge-based "paternal" regulations can be sufficient to induce sufficient behavioral changes at the individual level).

86. Some theorists, applying an economic-theory framework to these interventions, would describe this sort of intervention as "first best"-targeting a limited market failure with a choiceframing structure and limiting the second-order effects of maintaining that structure. Prabhat Jha et al., The Economic Rationale for Intervention in the Tobacco Market, in ToBAcCo CoNtrol in Developing Countries 153, 153-54 (Prabhat Jha \& Frank J. Chaloupka eds., 2000). 
also try to influence individual food consumption behaviors by shaping attitudes toward high calorie foods, identifying negative social norms about high calorie foods and poor food choices, and highlighting the ability of individuals to make better choices for themselves or at least be aware of the food choices they make. ${ }^{87}$ Finally, calorie count laws and the requirements they place on food retailers create social meaning for society at large and individual consumers by highlighting calorie counting and food consumption choices as a national public health issue.

The reason for these recent interventions is obvious to any casual observer. ${ }^{88}$ Today's food and diet related public health interventions in cities and states across the country grew out of an understanding that individuals have become less healthy with respect to food behaviors. The availability of cheap, easy, and frequently deep-fat-fried, fast-food options has supplanted the now distant tradition of home cooked meals. ${ }^{89}$ Not only are the choices presented becoming less healthy, but individuals are also making poorer choices more frequently. ${ }^{90}$ Some consumer populations are captive markets; public school students often have no real option but to accept what is fed to them by school cafeterias where the bottom line effectively dictates that adults make choices for children regardless of whether those choices are optimal. ${ }^{91}$ State interventions seek to restrict or modify this choice set through a variety of methods and for a few key reasons. ${ }^{92}$

87. Alan R. Kristal et al., Trends in Food Label Use Associated with New Nutrition Labeling Regulations, 88 Aм. J. Pub. HeAlth 1212, 1212, 1214-15 (1998) (showing a small effect of these labels on consumption).

88. Among contributors to causes of death in the United States, poor diet (26\%), high body mass index $(14 \%)$, and physical inactivity $(8.8 \%)$ are all among the top ten. U.S. Burden of Disease Collaborators, The State of U.S. Health, 1990-2010: Burden of Diseases, Injuries, and Risk Factors, 310 J. Am. Med. Ass'n 591, 596 (2013).

89. See Joanne F. Guthrie et al., Role of Food Prepared Away from Home in the American Diet, 1977-78 versus 1994-96: Changes and Consequences, 34 J. Nutr. Educ. BeHAv. 140, 142 (2002) (finding that out-of-home dining rose from $18 \%$ in the 1970 s to $32 \%$ by the 1990 s).

90. Id. at 140 .

91. See Melissa Mortazavi, Consuming Identities: Law, School Lunches, and What It Means To Be American, 24 Cornell J.L. \& Pub. Pol'y 1, 3-4 (2014) (discussing the social and political impact of food legislation in the school lunch context). See generally Rebecca L Goldberg, No Such Thing as a Free Lunch: Paternalism, Poverty, and Food Justice, 24 Stan. L. \& Pol'y Rev. 35 (2013) (addressing the policy intersection between anti-obesity and food justice advocates); Rebecca Edwalds, Note, Restructuring Local School Wellness Policies: Amending the Kids Act To Fight Childhood Obesity, 47 U. Mich. J.L. ReForm 1051 (2014) (examining, critiquing, and proposing amendments to current federal laws regarding childhood obesity).

92. See, Mitchell Landsberg \& Monte Morin, School Soda, Junk Food Bans Approved, L.A. Times, Sept. 7, 2005, http://articles.latimes.com/2005/sep/07/local/me-junkfood7. 
Recognizing that children and adults alike were suffering increasingly severe health consequences from food and diet related behaviors, public health advocates pivoted to these new interventions to more directly impact health outcomes. Some interventions were prompted by grassroots organizing, such as schools responding to parent petitions to improve the quality of school lunches. ${ }^{93}$ Other interventions responded to burgeoning health care costs imposed on state and local budgets. ${ }^{94}$ Because food and diet behaviors of individuals directly cause, contribute to, or exacerbate conditions such as heart disease, stroke, and diabetes, lawmakers have a variety of economic incentives to use public health law interventions to coerce optimal behavior thereby reducing budget expenditures. But, most of these interventions simply nudge the public. If the public supports these laws, listens to the implicit and explicit government communications about the effects of these laws, and understands the individual benefits of diet and health behavioral changes, then the expected public health outcomes should follow. ${ }^{95}$ Thus, none of these diet-related public health law interventions rely directly on deterrence theory, legitimacy, or even direct economic incentives, ${ }^{96}$ providing a useful baseline metric for applying an individual level, sociodemographic, political psychology approach to law support and behavior adoption and rejection.

\section{B. Food and Diet Intervention Trends}

The public health interventionist model in the obesity space is best captured by the efforts of large-scale and visible government interventions, such as those of New York City during the past fifteen years. ${ }^{97}$

93. See e.g., Mortazavi, supra note 91 , at 42.

94. For example, New York City's public-health department conducted a cost-benefit analysis to determine whether its proposed soda-ban would create significant municipal budget savings. See, e.g., In re N.Y. Statewide Coalition of Hispanic Chambers of Commerce v. N.Y.C. Dep't of Health \& Mental Hygiene, 16 N.E.3d 538 (N.Y. 2014).

95. But see Gary M. Lucas, Jr., Paternalism and Psychic Taxes: The Government's Use of Negative Emotions to Save Us from Ourselves, 22 S. CAL. InTERDIs. L.J. 227, 228, 230 (2013) (expressing skepticism that paternalistic public health interventions will succeed in their goals).

96. But, research and experiments in this space suggest that economic incentives may indeed change behavior with or without a law-mandated educational regime. See, e.g., Etienne J. Phipps et al., Impact of a Rewards-Based Incentive Program on Promoting Fruit and Vegetable Purchases, Ам. J. Pub. Health, Jan. 2015, at 166, 169-71 (describing the results of a study that provided financial incentives for low-income residents to eat healthier).

97. See, e.g., Diller, supra note 79, at 1136-37 (discussing the "meteoric" rise of menu-labeling legislation); Thomas R. Frieden et al., Public Health in New York City, 2002-2007: Confronting Epidemics of the Modern Era, 37 Int. J. Epidemiology 966 (2008); see also Sara Jo Dunstan, Comment, Big Brother Takes a Bite out of the Big Apple and Gets a Worm: Can Any Government Body Regulate Portions?, 55 S. Tex. L. Rev. 553, 555, 556-58 (2014) (discussing New York City's proposed soda ban); Hery (Michelle) Min, Note, Large-Sized Soda Ban as an Alternative to Soda Tax, 23 Cornell J.L. \& Pub. Pol'y 187, 190-92 (2013) (discussing the same). 
Of these varied interventions, those focused on the nexus between sugary soda and obesity, and between the quantity of consumption and overall obesity, provide the firmest ground for further study. ${ }^{98}$

Interventions with respect to outright prohibitions about the types of food that can be purchased or sold are obviously rare. The sole exception revolves around sweetened beverages and efforts to restrict sales generally or in communities at risk for overconsumption. Further, these interventions are typically focused on marginalized or politically underrepresented populations, such as those receiving government assistance, which raises questions about whether sociodemographic membership correlates with the application of coercive, rather than persuasive, approaches to health behavior modification. ${ }^{99}$

The broader soda law intervention movement developed in two parts: (1) an effort to restrict sales within schools; and (2) an effort to restrict sales more generally. ${ }^{100}$ A more limited set of restrictions tied to the location of machines in areas with school-age populations has proven more successful. Soda bans in schools have faced somewhat less opposition and are in place in large states such as California ${ }^{101}$ and Texas, ${ }^{102}$ as well as large cities in smaller states, like Maine. ${ }^{103}$ Building on this movement to restrict overly sugary beverages through outright legal prohibition, governing officials of various school sys-

98. Of course, there are a variety of other interventions in this space, but they will not be fully discussed in this Article. See, e.g., James G. Hodge et al., New Frontiers in Obesity Control: Innovative Public Health Legal Interventions, 5 Duke F. For L. \& Soc. Change 1, 1-2 (2013) (reviewing current public health law interventions addressing obesity); Kevin W. Ryan et al., Arkansas Fights Fat: Translating Research into Policy to Combat Childhood and Adolescent Obesity, 25 Health Aff. 992 (2006) (reviewing Arkansas' creation of state coalitions to gather the best evidence to devise the best anti-obesity policies).

99. See, e.g., Nancy Kass et al., Ethics and Obesity Prevention: Ethical Considerations in 3 Approaches to Reducing Consumption of Sugar-Sweetened Beverages, Ам. J. Pub. Health, May 2014, at 787, 791 (2014) ("[these approaches send] a public policy message that poor people require government intervention to manage their food choices whereas higher-income persons do not.").

100. A more recent movement to tax soda and a variety of other beverages shall not be discussed here because they are in their nascent stages and thus lack long-term trend evidence. However, they may prove to be a fruitful line of alternative inquiry in the future if these measures are adopted and prove more successful. See, e.g., Amanda Covarrubias, Results Mixed on California Soda Taxes, Fracking, Marijuana Measures, L.A. Times, Nov. 5, 2014, http://www.latimes.com/la-me-pol-election-notbeook-20141106-story.html (describing efforts in 2014 to enact soda taxes in Berkeley and San Francisco, California).

101. Tom Fudge, California Bans Soda in Schools, KPBS (July 1, 2009), http://www.kpbs.org/ news/2009/jul/01/california-bans-soda-schools/.

102. Eva Ruth Moravec, Sugary Drinks Banned from Texas Schools, Houst. Chron.: Tex. Pol. (May 21, 2013), http://blog.chron.com/texaspolitics/2013/05/sugary-drinks-banned-fromtexas-schools/.

103. Caroline Cornish, Portland Schools Ban Soda Sales, Aim for Healthier Snacks, WLBZ2 (Aug. 17, 2012, 5:40 PM), http://archive.wlbz2.com/news/local/story.aspx?storyid=211089. 
tems in California, Colorado, Florida, Washington, and West Virginia have also considered banning, or have banned, flavored milk. ${ }^{104}$ Still, other jurisdictions are engaging the issue by further restricting choice through law, such as banning "junk food" more generally, and thus shifting student consumption behavior. ${ }^{105}$

Extending this reasoning, former New York City mayor, Michael Bloomberg, proposed a broader intervention in May 2012.106 The proposed amendment to New York City's Health Code included an explicit statement of legislative purpose highlighting the public health impact goals of the law. ${ }^{107}$ The intervention was straightforward: through regulation, the City would prohibit fast-food vendors from selling sugary drinks in containers larger than sixteen ounces. The message to the public was also straightforward. Obesity was a public health epidemic in New York City, sugary drinks and a lack of vigorous physical activity were direct causes of obesity, and, moreover, the government could improve the public health by eliminating one source of the problem: large portions of sugary drinks. 108

The model for this intervention would be the elimination of individual choice by regulation and promotion of a behavioral shift either by the general reduction in consumption of all sugary beverages (regardless of size) or by the choice of consumers to engage in obesity-reducing behavior, such as exercise or the complete elimination of sugary drinks in personal diets. Thus, the intervention provided for both a formal legal prohibition to improve public health as well as an educa-

104. Christina Hoag, More Schools Consider Flavored Milk Bans, HufFington Post (May 9, 2011, 9:18 AM), http://www.huffingtonpost.com/2011/05/09/flavored-milk-in-schools-_n_859311 .html.

105. See, e.g., Landsberg \& Morin, supra note 92 (discussing two California bills to make lunches and snacks healthier by limiting the sale of junk food on school campuses). See generally Ctrs. for Disease Control \& Prevention, Competitive Foods and Beverages in U.S. Schools: A State Policy Analysis (2012), http://www.cdc.gov/healthyyouth/nutrition/pdf/ compfoodsbooklet.pdf.

106. N.Y. Dep't of Health \& Mental Hygiene, Notice of Adoption of an Amendment (\$ 81.53) to Article 81 of the New York City Health (Mar. 12, 2013), http:// rules.cityofnewyork.us/content/establishing-maximum-size-sugary-drinks-0.

107. Id. The amendment's "Statement of Basis and Purpose" does two things: (1) it outlines the following main food and diet-related problems: ((a) "Obesity is epidemic among New Yorkers and the consequences are devastating"; (b) "Sugary drinks are a leading driver of the obesity epidemic and are associated with dangerous chronic diseases"; (c) "New Yorkers are consuming excessive quantities of sugary drinks"; (d) "Portion sizes are increasing - and bigger portions lead to greater consumption of sugary drinks") and (2) it identifies the solutions and goals of the proposed intervention: "[t]he purpose of the amendment is to address the obesity epidemic among the City's residents by limiting the maximum size of sugary beverages ...." Id.

108. Michael M. Grynbaum, New York Plans to Ban Sale of Big Sizes of Sugary Drinks, N.Y. Times, May 30, 2012, http://www.nytimes.com/2012/05/31/nyregion/bloomberg-plans-a-ban-onlarge-sugared-drinks.html?_r=1. 
tion-information model: changing public behavior through education and government persuasion.

New York City's interventionist approach was met with strong resistance from industry groups and those who critiqued the power of big government interventions regardless of the issue. ${ }^{109}$ Public communications about the city's intervention were primarily limited to city officials and public health advocates who engaged the issue in the press. Soda manufacturers, an obvious and major opponent of the law, argued in a preemptive lawsuit that the proposed law was "an end-run around the City Council, reflecting an overreaching 'nanny administration." "110 A New York state appellate court ruled that the city's "Board of Health exceeded the scope of its regulatory authority by adopting" the soda ban. ${ }^{111}$ New York City's attempts to limit sales of large-sized sodas were first enjoined, and then ultimately abandoned, as a result of court decisions. ${ }^{112}$ One reviewing court reasoned that "an administrative agency exceeds its authority when it makes difficult choices between public policy ends, rather than finds means to an end chosen by the Legislature."113 Despite this judicial rejection of one food and diet intervention, food and diet interventions can still take divergent forms rooted in "nudge" like approaches. For example, while a soda-ban proposal may not typically be thought of as a "nudge-based" intervention, a calorie-count proposal would be. ${ }^{114}$

Public health law interventions with respect to calorie counts are also of fairly recent vintage and rely on an assumption that the public supports these interventions, pays attention to the information provided, and understands how to correctly use calorie counts in a manner that can lead to better consumption decisions. ${ }^{115}$ Calorie count and menu labeling requirements have been enacted frequently in re-

109. Id.

110. Declaratory Judgment Petition of Plaintiff-Petitioner at 1. In re N.Y. Statewide Coalition of Hispanic Chambers of Commerce v. N.Y.C. Dep’t of Health \& Mental Hygiene, 970 N.Y.S.2d 200 (2013).

111. In re N.Y. Statewide Coal. of Hispanic Chambers of Commerce v. N.Y.C. Dept. of Health \& Mental Hygiene, 16 N.E.3d. 538, 549 (N.Y. 2014).

112. Michael M. Grynbaum, New York's Ban on Big Sodas Is Rejected by Final Court, N.Y. Times, June 26, 2014, http://www.nytimes.com/2014/06/27/nyregion/city-loses-final-appeal-onlimiting-sales-of-large-sodas.html.

113. In re N.Y. Statewide Coal., 16 N.E.3d at 549.

114. See Thaler \& Sunstein, supra note 2, at 262.

115. See Lauren F. Gizzi, Comment, State Menu-Labeling Legislation: A Dormant Giant Waiting To Be Awoken by Commerce Clause Challenges, 58 CATH. U.L. Rev. 501, 514-19 (2009) (discussing contemporary city and state menu-labeling legislation efforts and the motivations behind them - for example, noting that the Board of Health rationalized New York City's menu labeling law based on its duty to "prevent[ ] and control[ ] diseases" and its "interest in consumers' informed decision-making"). 
cent years. Cities such as New York City, 116 Philadelphia, and Seattle, as well as states such as California, ${ }^{117}$ Maine, and Oregon independently created laws requiring certain food vendors to display calorie counts. Seattle passed a city ordinance requiring chain restaurants to post calorie counts for all menu items, and research showed this menu labeling impacted caloric content of these items. ${ }^{118}$ Further, the effect of these interventions impacted consumers in a variety of ways, including some chain restaurants reducing portion sizes and modifying recipes to include lower-calorie ingredients. ${ }^{119}$ Other states that have considered similar interventions include: Hawaii, Illinois, Iowa, Massachusetts, Michigan, New York, Tennessee, Vermont, and Washington. ${ }^{120}$ Yet the effect of these interventions on actual behavior is decidedly uncertain. ${ }^{121}$

Public health law interventions in this domain also include federal action, which is unlike other public health law interventions discussed in this Article. Prompted by a much debated provision in the Patient Protection and Affordable Care Act (ACA), ${ }^{122}$ certain food retailers moved toward labeling calorie counts for products. ${ }^{123}$ Changes in the chain food retail sector first occurred because the ACA's language specified that chain restaurants above a certain size would eventually be subject to calorie count provisions. ${ }^{124}$ Some smaller independent food retailers have now begun to participate in the change volunta-

116. Press Release, Office of Governor Edmund J Brown, Governor Signs Legislation Promoting Nutrition and Healthier Options, http://gov.ca.gov/news.php?id=10700 (last visited July 19, 2015) (quoting Gov. Schwarzenegger's introductory comments on California's menu-labeling law, highlighting that the law would allow people to "make informed decisions about what to eat" in restaurants that "will lead to healthier options on the menu and it will benefit all of the people").

117. L.R., Menu Labelling: New York's Calorie Counting, Economist (July 28, 2011, 12:14 PM) http://www.economist.com/blogs/babbage/2011/07/menu-labelling.

118. Sarah Kliff, Study: After Menu Labeling, Healthier Restaurant Offerings, WAsH. Post (July 19, 2012), http://www.washingtonpost.com/blogs/wonkblog/wp/2012/07/19/study-aftermenu-labeling-healthier-restaurant-offerings/.

119. Id.

120. Matthew Gever, Legislators Counting on Nutrition Information to Curb Obesity, 29 State Health Notes, Sept. 15 2008, http://www.ncsl.org/Portals/1/documents/health/shn/ shn523.pdf.

121. See, e.g., Brian Elbel et al., Calorie Labeling and Food Choices: A First Look at the Effects on Low-Income People in New York City, 28 Health AfF. w1110, w1117 (Web Exclusive 2009).

122. Patient Protection and Affordable Care Act, Pub. L. No. 111-148, § 4205, 124 Stat. 119 (2010) (codified at 21 U.S.C. § 343-1 (2012)) ("Nutrition labeling of standard menu items at chain restaurants").

123. See, e.g., McDonald's USA Nutrition Facts for Popular Menu Items, McDonAlds.com (July 19, 2015), http://nutrition.mcdonalds.com/getnutrition/nutritionfacts.pdf.

124. Patient Protection \& Affordable Care Act, § 4205. 
rily. ${ }^{125}$ The FDA recently issued new rules for menu labeling requirements to expand the existing requirements used in chain restaurants nationwide, even though the efficacy of these interventions is uncertain. ${ }^{126}$

Thus, most of these interventions share one of two key features: (1) elimination of a negative source of diet as a source of harm reduction; or (2) a more visible (forced) form of individual education about the calorie content of one's diet. ${ }^{127}$ And, though other studies have explored the public's support for calorie counts, ${ }^{128}$ few studies have done so across multiple domains or within the time frame most salient for the FDA's recent rulemaking. Therefore, this Section seeks to answer some basic questions about the public's support for these interventions, including whether the public supports them and whether the law's "education as intervention" function works as intended.

\section{Food and Diet Interventions-Survey Questions and Results}

Survey respondents were presented with three questions about proposed public health law interventions. These interventions were framed to raise awareness of the explicit political choice set and reasoning that were presented as justifying the interventions.

\section{Food and Diet Questions}

Some people say that the government should create laws that will help people eat healthier food and lead healthier lives, while others say that government should not interfere in an individual's choice about how to live- or how to eat. Here are a few laws about health and food choices that have been or may be proposed where you live. For each, please indicate how you would feel about such a law being enacted.

Respondents were then provided with three question frameworks about a variety of public health interventions, tied to the interventions discussed above.

125. See, e.g., Brady Dennis, Calorie Counts: Coming to a Restaurant, Movie Theater, Vending Machine Near You, WAsH. Post, Nov. 24, 2014, http://www.washingtonpost.com/national/healthscience/calorie-counts-coming-to-a-restaurant-movie-theater-vending-machine-near-you/2014/ 11/24/e5bd25ae-7415-11e4-a5b2-e1217af6b33d_story.html.

126. See id.

127. A more charitable framing might suggest that the display of information helps to shape norms or behaviors by changing the default option. ThALER \& Sunstein, supra note 2, at 7-8.

128. See, e.g., Amir Goren et al., Predicting Support for Restricting Food Marketing to Youth, 29 Health Aff. 419 (2010); J. Eric Oliver \& Taeku Lee, Public Opinion and the Politics of Obesity in America, 30 J. Health Pol. Pol'y L. 923 (2005); Christina A. Roberto et al., Rationale and Evidence for Menu-Labeling Legislation, 37 Am. J. Prev. Med. 546 (2009). 
1. Requiring fast-food restaurants, such as McDonald's, to post calorie counts on their menus.

2. Requiring sit-down chain restaurants, such as Red Lobster, Chili's, or Applebee's, to post calorie counts on their menus.

3. Eliminating soda machines from public schools and other public facilities frequented by children.

Responses were coded on a Likert scale from 1: strongly support the law, to 7: strongly oppose the law.

Respondents overwhelmingly supported each of the three proposed interventions, with policy support means as follows:

Table 1. Food and Diet Interventions (Mean Responses)

\begin{tabular}{lcc}
\hline Proposed Intervention & Response Mean & Std. Error \\
\hline Fast-Food Calorie Counts & 2.29 & 0.039 \\
Sit-Down Calorie Counts & 2.41 & 0.039 \\
Soda Ban & 2.75 & 0.044 \\
\hline
\end{tabular}

Respondents were then asked a follow-up question about whether they would actually use calorie count information as public health law advocates would hope: to alter behavior and inform and improve dining habits, particularly outside of the home.

\section{Calorie Count Question}

When calorie information is available for your meal or snack choices when you eat out at fast-food or sit-down restaurants, do you:

1. Read it and use it to make choices about what to eat.

2. Read it and consider it as a small factor in what to eat.

3. Read it but don't really use it at all.

4. Don't read it or don't eat out.

Responses to the above question can be grouped into three calorie count "use" categories: routine use, partial use, or rare and nonuse (collapsing choices 3 and 4 above). Of the 2,027 respondents, only 822 $(40.55 \%)$ responded that this information is routinely both read and utilized, while $509(25.11 \%)$ responded that they either rarely or never use the information. Even the 696 (34.34\%) partial users indicated that their use of the information was just one of many factors in their decision-making calculus. 


\section{Conclusion-Food and Diet Interventions and Public Opinion}

The results above suggest that information in this policy space, by itself, is unlikely to change the majority of the public's behavior in this domain. ${ }^{129}$ Yet this individual rejection of information strongly contrasts with public support for the provision of the information, which leads to a conundrum. Public health advocates and policy makers continue to pursue this type of intervention (due to a lack of public resistance to the policy) even as the public passively expresses this resistance (with respect to individual behavior).

Thus, the abovementioned responses suggest broad support (mediated by varying strength) for a variety of education-based public health law interventions, including one that contains both an explicit prohibition on behavior (soda bans) as well as a subtle implicit norming component (by removing soda machines, the public will become aware that overconsumption of soda by children is harmful or negative and will adjust behavior accordingly). But, the value of interventions may be minimized if the intervention is centered on the provision of information to educate the public and encourage behavioral change, and the public, by and large, does not want to utilize this information to inform its behavior. Further, interventions targeted at more vulnerable populations, children for example, did not receive an expected commensurate increase in public support compared to the calorie-count interventions (targeted at adults), despite the perception that the public supports a more paternal public health approach for younger populations. In short, these results provide some initial, broad explanations for why these interventions have not been shown to substantially affect the public. ${ }^{130}$

Perhaps the somewhat voluntary nature of the food and diet interventions, coupled with the focus on vulnerable populations, might account for widespread support. Nonetheless, support for the control intervention (smoking) is similar to support for the nudge-based food and diet intervention. But, taking the public's overwhelming support as a positive sign for interventionists, even if the law's efficacy is uncertain, we might then expand the analysis by broadening the scope of

129. E.g., Eric A. Finkelstein et al., Mandatory Menu Labeling in One Fast-Food Chain in King County, Washington, 40 Am. J. Prev. Med. 122, 126 (2011) (finding little evidence of a local calorie-count law changing consumer behavior for one restaurant); Pooja S. Tandon et al., The Impact of Menu Labeling on Fast-Food Purchases for Children and Parents, 41 Am. J. Prev. MED. 434, 435 (2011) (finding that a menu-label regulation increased awareness but not the amount of calories purchased and consumed).

130. E.g., Helen L. Walls et al., Public Health Campaigns and Obesity - a Critique, 11 BMC Pub. Неalth 136, 136 (2011), http://www.biomedicalcenttral.com/1471-2458/11/136 (finding little evidence regarding the efficacy of these interventions). 
intervention. If the public is relatively accepting of this law intervening in areas with clear public health costs and consequences, how might it respond to new initiatives in an area for which the public's awareness of these costs and consequences is less certain?

So, with respect to youth sports TBI laws, should we expect the public's support to be weaker given the relative novelty of these interventions or stronger given their focus on children? With respect to the relatively new nature of these interventions, if support for more innovative public health law interventions is in part a function of time, these interventions should receive less support. ${ }^{131}$ Further, if the interventions are unfamiliar, less voluntary, or intrude on a perceived sacred sphere, perhaps they will receive less support. On the other hand, if we expect resistance to these interventions to be a function of the degree of paternalism in the nudge, this resistance should be minimized when the intervention is directed at a more vulnerable population: children. To test these assumptions and to include a more direct measurement of the likelihood that public support for public health law interventions could be increased through the use of either trusted messengers or the insertion of scientific data in the dissemination of policy, two survey experiments were conducted as described in Part VI. ${ }^{132}$

\section{Youth Sports TBI Laws-Assessing Support for Intervention by Messenger and Message}

\section{A. Theories of Youth Sports Interventions}

Youth sports TBI laws, an intervention of relatively recent vintage, rely on a combination of proscriptive techniques as well as a familiar choice-optimizing framework delivered through mandatory education requirements. Generally speaking, youth sports TBI laws attempt to impact individual behaviors indirectly by raising awareness about the potential harm of TBIs on youth who participate in organized sports. ${ }^{133}$ This awareness can be highlighted to both youth sports par-

131. But see Jim Travers, Michigan Motorcycle Injury Claims Rise with Helmet Law Repeal, Consumer ReP. (June 03, 2013, 03:08 PM), http://www.consumerreports.org/cro/news/2013/06/ michigan-motorcycle-injury-claims-rise-with-helmet-law-repeal/index.htm (describing the partial repeal of a motorcycle helmet law and commensurate rise in injury claims).

132. See infra notes $133-57$ and accompanying text.

133. See, e.g., WAsh. Rev. Code $§ 28$ A.600.190 (2014). Known as the Zackery Lystedt Law, this was the first broad youth sports TBI law. See Lowrey \& Morain, supra note 15, at 290. The Lystedt Law begins with a section discussing the prevalence and significance of concussions and head injuries in young athletes. Many states followed and enacted a youth sports TBI law modeled on this one, and all state laws have included a preamble highlighting the potentially 
ticipants and their parents. ${ }^{134}$ Youth sports TBI laws also try to influence individual youth sports behaviors by shaping attitudes toward new or improved safety measures, identifying negative social norms about unsafe sporting behaviors, and highlighting the ability of individuals to influence choices made by youth sports participants, coaches, and parents. Finally, youth sports TBI laws and the requirements they place on youth sports organizers and participants create social meaning for the general public and individual participants by highlighting youth sports TBIs as a national public health issue worthy of increased public health attention and concomitant legal regimes. ${ }^{135}$

\section{B. Youth Sports Intervention Trends}

Beginning in the late 2000s, ${ }^{136}$ a heightened recognition of the potentially devastating consequences of secondary-impact brain injuries in youth sports led to the rapid enactment of youth sports TBI laws across the country. The greater visibility about stories of injured youth athletes, coupled with the support of an array of outside interest groups, led lawmakers to pass these laws at a fairly quick pace. Affected youth athletes, their families, lobbyists, and legislators worked together to develop youth sports TBI laws that used education and voluntary behavioral shifts as the primary method of achieving optimal results. ${ }^{137}$ However, these laws significantly overlooked the domain of primary prevention, which would have ultimately required a more coercive approach and would have likely included restrictions not previously contemplated by the general public. ${ }^{138}$

catastrophic consequences of concussions. See Hosea H. Harvey, Refereeing the Public Health, 14 Yale J. Health Pol'y L. \& Ethics 66 (2014).

134. See N.J. Rev. StAT. § 18A:40-41.1 (2013) (calling for "athletes, coaches, and parents and guardians" to become "educated about the nature and treatment of concussions and other sports-related head injuries").

135. See, e.g., id. (noting in the preamble to the state's youth sports TBI law, legislative findings highlight CDC data on sports-related concussions).

136. But see David Orentlicher \& William S. David, Concussion and Football: Failures to Respond by the NFL and the Medical Profession, 8 FIU L. REv. 23, 29-35 (2013) (describing a lag between the growing scientific consensus and the slow adoption of changes to policy and practice with respect to concussions).

137. See generally Erin P. Andrews, Note, Avoiding the Technical Knockout: Tackling the Inadequacies of Youth Concussion Legislation, 58 N.Y.L. ScH. L. REv. 417 (2013/2014) (discussing the differences, ambiguities, and inadequacies in current state legislation).

138. These laws also do not resolve the tension between the science of concussions and the quality of protective equipment. See Brian Gruley, The Truth About the Safety Ratings That Sell Football Helmets, BloomberG: Bus. (Jan. 28, 2015), http:/www.bloomberg.com/news/features/ 2015-01-28/the-controversial-safety-ratings-that-sell-football-helmets. See generally Samuel D. Hodge \& Shilpa Kadoo, A Heads-Up on Traumatic Brain Injuries in Sports, 17 J. HeAlth CARE L. \& POL'Y 155 (2014) (noting the ineffectiveness of the existing array of youth sports TBI guidelines). 
From 2009 to 2014, all fifty states and the District of Columbia passed laws designed to minimize the consequences of youth sports TBIs. ${ }^{139}$ The first youth sports TBI law, created by Washington State, was prompted by the severe injury of one specific youth athlete. ${ }^{140}$ Subsequent state laws mirrored the initial Washington law but were also shaped by NFL lobbying and legislative influence. ${ }^{141}$ These laws are organized around three core elements: (1) annual education of athletes and parents; (2) mandatory removal of athletes suspected of having a TBI from play; and (3) clearance by a designated health professional before an athlete with a TBI can return to play. ${ }^{142}$ In addition to these state law developments, public opinion and sentiment about the appropriate scope of intervention was also influenced by highly publicized lawsuits between professional football players and the National Football League (NFL). ${ }^{143}$ Similar suits were filed by players in the National Collegiate Athletic Association (NCAA), ${ }^{144}$ National Hockey League (NHL), ${ }^{145}$ Fédération Internationale de Football Association (FIFA), ${ }^{146}$ and high school football leagues. ${ }^{147}$

139. Harvey, supra note 133; LAwATLAs, http://lawatlas.org/query?dataset=sc-reboot (last updated May 1, 2015) (noting that as of May 2015, every state and the District of Columbia passed a law intended to protect youth athletes from repeat TBIs).

140. Sheila Mickool, The Story Behind the Zackery Lystedt Law, Seattle Mag., Fall/Winter 2012, http://www.seattlemag.com/article/story-behind-zackery-lystedt-law.

141. See Harvey, supra note 133, at 98-99.

142. Hosea H. Harvey, Reducing Traumatic Brain Injuries in Youth Sports: Youth Sports Traumatic Brain Injury State Laws, January 2009-December 2012, 103 Ам. J. Pub. HeAlth e1, e2 (2013).

143. Patrick Hruby, The NFL Dodges on Brain Injuries, AtLantic (Sept. 4, 2014), http://www .theatlantic.com/entertainment/archive/2014/09/the-nfls-concussion-settlement-not-acceptable/ 379557/; see also Daniel Gandert \& Esther Kim, The NFL's Headache: Issues with California Workers' Compensation for Continuous Head Traumas in Former Professional Football Players, 45 U. Tol. L. Rev. 57, 57 (2013) ("Head traumas have become an increasingly visible problem for the NFL.").

144. NCAA Settles Head-Injury Lawsuit, ESPN (July 29, 2014), http://espn.go.com/collegesports/story/_/id/11279710/ncaa-settles-head-injury-lawsuit-create-70-million-fund. See generally Elizabeth Etherton, Systematic Negligence: The NCAA Concussion Management Plan and Its Limitations, 21 SpORTs L.J. 1, 8-26 (2014) (addressing inadequacies and limitations of the NCAA's concussion policies and comparing them to state and federal legislation); K. Adam Pretty, Note, Dropping the Ball: The Failure of the NCAA To Address Concussions in College Football, 89 Notre Dame L. Rev. 2359, 2361-67 (2014) (highlighting the failure of the NCAA to respond to medical professional, institutional, and societal pressures to improve their organizational concussion policies).

145. Chris Peters, NHL Hit with Another Class-Action Suit Tied to Brain Injuries, CBS: SPORTs (July 30, 2014, 6:49 PM), http://www.cbssports.com/nhl/eye-on-hockey/24643748/nhl-hitwith-another-class-action-suit-tied-to-brain-injuries.

146. Darren Heitner, Class Action Concussion Lawsuit Filed Against FIFA and U.S. Soccer Associations, Forbes (Aug. 27, 2014, 11:01 AM), http://www.forbes.com/sites/darrenheitner/ 2014/08/27/class-action-concussion-lawsuit-filed-against-fifa-and-u-s-soccer-associations/.

147. Sarah Ganim, Class-Action Lawsuit Filed over High School Football, CNN, http://edition .cnn.com/2014/12/01/us/concussion-lawsuit-high-school-football/ (last updated Dec. 2, 2014). 
As with the other interventions discussed supra, I designed a set of survey questions to test whether the public would support a particular set of public health law interventions in this policy domain and whether there was variance across sociodemographic group responses depending on the nature and scope of the intervention. But, unlike the domains discussed supra, public opinion about these interventions was gauged through a series of experiments designed to capitalize on previous findings and alter methods of communicating changes in law and the scientific basis for the intervention.

With respect to the within-survey experiments infra, a few key findings were expected. Because Americans have a wide variety of news source groups, which evidence suggests influence individual opinion, I expected to find that as the messenger of the proposed intervention changes, so too will the overall level of support for the intervention. ${ }^{148}$ Three groups of messengers were identified: (1) public health advocates or groups; (2) doctors or physician groups; and (3) Michelle Obama or other political figures. It was expected that support for the intervention would be tied to individual beliefs about the efficacy of the messenger such that political figures would have the least impact, doctors the most impact, and public health advocates occupying an uncertain center. ${ }^{149}$ Further, Michelle Obama was chosen as an appropriate messenger because of her visibility within this space as well as to test whether ideological opposition to her-as a person-would be associated with either reduced policy support or reduced law compliance. ${ }^{150}$ With respect to the experiment about the value of additional information influencing public opinion toward adoption of a new intervention, it was expected that smokers, above all, would be the most resistant to new scientific information for a variety of reasons. Put differently, most Americans rely on a trusted figure for in-

148. But see Nan D. Hunter, Health Insurance Reform and Intimations of Citizenship, 159 U. PA. L. REv. 1955 (2011) (suggesting that the intervention is assessed broadly and in relationship to individual conceptions of citizenship and that the messenger (state versus federal government) may not be as salient as expected).

149. Background questions in the survey indicated that more than $75 \%$ of survey respondents received health information from their doctor, notwithstanding the complicated nature of that relationship. See Charity Scott, Doctors as Advocates, Lawyers as Healers, 29 Hamline J. PuB. L. \& PoL'y 331 (2008) (explaining a physician's fiduciary duty to his patient and examining the role of a doctor as an advocate). No other methods of gathering information were consistent across even $50 \%$ of the survey subpopulation.

150. See James Oliphant, Conservatives Heap Criticism on Michelle Obama's Campaign Against Childhood Obesity, CLeveland.com (Feb. 27, 2011, 2:00 AM), http:/www.cleveland .com/nation/index.ssf/2011/02/conservatives_heap_criticism_o.html; Kathleen Parker, Opinion, Michelle Obama's 'Let's Move Goes Too Far, WAsh. Post, May 30, 2014, http://www.washington post.com/opinions/kathleen-parker-michelle-obamas-lets-move-goes-too-far/2014/05/30/082576 70-e832-11e3-a86b-362fd5443d19_story.html. 
formation, and thus, this experiment provided an opportunity to learn two things: (1) whether the title and description of that expert matters; and (2) whether the information (the science) actually matters in individual decision making and opinion formation.

\section{Youth Sports Interventions Experiment-The Messenger}

The experiment divided the overall sample into three roughly equal groups that received the same four-suggestion set but varied the messenger. The doctor (657 respondents), public health (668 respondents), and Michelle Obama (685 respondents) groups all contained roughly equal numbers of respondents and nonrespondents (ten, eighteen, and eleven respondents respectively). Respondents were presented with four questions about proposed public health law interventions with respect to youth sports rooted in a series of recently proposed or enacted interventions based on the Lystedt framework discussed supra. Because many of the states were passing public health law interventions at the time of the survey, the question sought to decouple those live debates from the question choice set. Therefore, respondents were asked about their support for these policies being adopted at the local school level. The questions were framed to explicitly raise awareness about the messenger of these laws and, when necessary, the explicit individual choice set presented by adoption of these laws.

Respondents were presented with a general summary and lead for the question as follows:

Recently, efforts have been made by a variety of public health officials and groups, such as [], to promote youth physical activity such as through organized sports or daily exercise. But [] also want to ensure that the activities are safe and do not lead to injuries or physical harm. The following are some suggestions that have been made to help make youth physical activity safer. For each suggestion, please indicate how you would feel about such a requirement being adopted by your local schools.

Within each bracket space above, the messenger was identified as:

(1) Public health officials and groups, such as the American Public Health Association;

(2) political figures and government officials, such as First Lady Michelle Obama; or

(3) doctors' and physicians' groups, such as the American Medical Association. 
Following the general lead above, respondents were then given the choice of how they would feel about particular suggestions being adopted by their local schools.

Suggestions were in the form of four choices framed as follows:

(1) Requiring annual physicals for children involved in organized school sports;

(2) requiring children who participate in contact sports to undergo special training about the risk of concussions or head injuries;

(3) requiring parents who coach grade school or high school organized sports to become certified in first-aid and prevention of injuries; or

(4) eliminating "high-risk" sports, such as football, from local schools.

Responses were coded on a Likert scale from 1: strongly support the law, to 7: strongly oppose the law.

\section{RESULTS}

The results of the four messenger experiments are provided in Table 2.

Table 2. Mean Differences by Messenger Across Policies

\begin{tabular}{lccc}
\hline Proposed Intervention & Doctors & Politicians & $\begin{array}{c}\text { Public } \\
\text { Health }\end{array}$ \\
\hline Annual Physical & $1.86(.051)$ & $1.93(.052)$ & $1.85(.054)$ \\
Parents First Aid & $1.81(.049)$ & $1.91(.053)$ & $1.74(.048)$ \\
Children TBI Information & $2.06(.054)$ & $2.17(.058)$ & $2.15(.056)$ \\
Eliminate Risky Sports & $5.10(.079)$ & $5.09(.079)$ & $5.20(.076)$ \\
$* \mathrm{p}<.05$ (none) & Mean (s.e.) & Mean (s.e.) & Mean (s.e.) \\
\hline
\end{tabular}

The consistency of responses across three of the four abovementioned questions undermines a central hypothesis of this Article: that the perceived quality of the messenger or advocate-or at least the differences between the type of advocate-would causally contribute toward an upward or downward shift in public opinion about various interventions. Indeed, other recent research confirms this finding: that the quality of the messenger, assuming that she retains some baseline of credibility, does not substantially affect individual opinion about certain public health law interventions. ${ }^{151}$

151. See Morain \& Mello, supra note 9, at 494, for example, applying a legitimacy framework to support new frontier public health interventions and finding little correlation between public 
But, there are apparently some areas that survey respondents feel that public health law should not touch, a sacred sphere, that is directly regulating the content of sports by eliminating them. Viewed through the lens of legitimacy, the public's perception of the proposed law (the ban) must reflect a belief that the regulatory authority is entitled to regulate the issue space, and this belief is a component of the authority's legitimacy. ${ }^{152}$ Thus, it is possible, perhaps even likely, that the public generally believes public health authorities, doctors, and politicians all equally lack both the expertise to persuade the public of their authority to propose this particular intervention and that such an intervention, regardless of who would propose or implement it, should not be the subject of government action. It may also be rooted in a broad consensus about the value of individual liberty, where laws that provide the most invasive form of liberty restraint are expected to produce the lowest levels of public support. ${ }^{153}$ It may reflect sociological norms about sports situated against a history of light touch or nonregulation of sports rules and norms. ${ }^{154}$ But, while general aversion to this particular policy may indeed reflect a fundamental rejection of regulatory legitimacy in this space, a general proliberty bias, or a sociological aversion to interference with sports norms, the relative strength of that rejection may be mediated by efforts to educate and inform the public of the reasoning behind the policy. Thus, the focus of the next experiment was to test the value of information and education within this policy space.

\section{Youth Sports Interventions Experiment-The Message}

As Professor Jeffrey Swanson and colleagues explain, in contested public health policy domains "people act on the basis of their beliefs, and they tend to support policies that assume those beliefs and perceptions to be true."155 Therefore, a related objective of this study was to evaluate the potentially positive impact that empirically rooted scientific information could have on increasing the public's support for

support for these interventions and individual perceptions of "the trustworthiness of public health officials, their record on respecting individual rights, or their performance generally."

152. See Tom R. Tyler \& Yuen J. Huo, Trust in the Law: Encouraging Public Cooperation with the Police And Courts 101-05 (2002).

153. Morain \& Mello, supra note 9, at 493 ("One key finding is that the greater the restraint a legal intervention imposes on individual liberty, the greater public opposition to the intervention is likely to be.").

154. See Kevin Brandwein, Goals and Obstacles in Legislating Concussion Management in Youth Sports, Willamette Sports L.J., Spring 2013, at 28, 43 (discussing the difficulty in changing sports cultural norms).

155. See Swanson et al., supra note 10, at 367. 
a public health law intervention that they previously opposed. ${ }^{156}$ Further, this message was designed as an alternative to the narrativedriven framework that led to the adoption of many states' youth sports TBI laws. ${ }^{157}$ Immediately after answering the question in subsection VI.C, respondents were asked to reconsider their policy support via the following question.

Following up on your response to the question above about eliminating high-risk sports, would it change your opinion if you knew that leading health experts have testified that the risk of permanent damage from low-level concussions in many high school sports means that there's a chance that children who play those sports may end up with long-term potential brain damage years later? If this statement was true, how would this affect your thoughts on eliminating 'high-risk' school organized youth sports?

Following the question lead above, all respondents were given the choice of identifying whether or not the information provided would influence their likelihood of supporting the adoption of the "eliminate high-risk sports" suggestion at the local school level. It was expected that if members of the public, primed on a given policy, were given further risk centered information about how a specific intervention would substantially change public health outcomes, they would be more likely to support the intervention due to this explicit risk framing. 158

The response categories for the question were as follows:

(1) I would be more inclined to support keeping those programs.

(2) I would be more inclined to get rid of those programs.

(3) It doesn't change my mind at all.

The experiment results indicated that 1,200 respondents $(58.45 \%)$ would not change their minds after being provided with this further information. Of the remaining, 597 respondents $(29.08 \%)$ indicated they would be more inclined to support the policy change, and only 256 respondents $(12.47 \%)$ indicated that they would be less likely to support the policy change. What then should the observer of opinion

156. See David Orentlicher, Health Care Law: A Field of Gaps, 19 Annals Health L. (SPeCIAL Issue) 1, 3-4 (2009-2010) (describing how public support for particular medical decisions or policies changes depending on how they are explained by doctors and lawmakers).

157. See generally David A. Hyman, Lies, Damned Lies, and Narrative, 73 InD. L.J. 797, 837-39 (1998) (describing the perils of the anecdote in the process of lawmaking).

158. See generally Kathleen E. Bachynski \& Daniel S. Goldberg, Youth Sports \& Public Health: Framing Risks of Mild Traumatic Brain Injury in American Football and Ice Hockey, 42 J.L. Med. \& Ethics 323 (2014) (analyzing risk frameworks and public health consequences of various risk frames). 
make of the fact that when given information that should sway individual opinion toward the policy, less than one-third of all respondents moved in the predicted direction?

\section{E. Conclusions About Youth Sports Interventions}

The results, when disaggregated by sociodemographic groups, tell a more nuanced story. Respondents who identified as liberal women were more likely to respond-with a statistically significant difference-that the information made a difference in the predicted direction. In contrast, those who identified as white, male, and conservative were the least likely to be swayed by the additional information. Putting these numbers in context, more than $70 \%$ of conservative respondents indicated that the information would make no difference. What should one make of this conservative resistance to more information, particularly when many theorists reject a simple sociodemographic aversion to science in political reasoning? To explore these potential confounding influences across the entire survey, this Article turns to analysis of the results separated by individual demographics, using a political psychology framework.

\section{Sociodemographic Variance and Public Support FOR LAW INTERVENTION}

\section{A. Race and Interventions}

Reflecting across the entire set of nine public health law intervention questions presented in this Article, racial differences emerge across half of them, particularly when racial differences are aggregated to a white group or an ethnic minority group identification. While no significant racial differences are found in the responses to law interventions involving calorie counts, annual physicals, and training of parents in first aid, white respondents were significantly more likely to oppose the remaining public health law interventions (smoking proposals, soda bans, youth sports risk-based education, and banning of sports) by comfortable margins, as shown in Table 3. 


\section{Table 3. Proposed Interventions \\ (Mean Responses by Race)}

\begin{tabular}{lccc}
\hline Proposed Intervention & $\begin{array}{c}\text { White } \\
\text { Mean (S.E.) }\end{array}$ & $\begin{array}{c}\text { People of } \\
\text { Color } \\
\text { Mean (S.E.) }\end{array}$ & $\begin{array}{c}\text { Mean } \\
\text { Difference }\end{array}$ \\
\hline Fast-Food Calories & $2.33(.049)$ & $2.19(.064)$ & \\
Sit-Down Calories & $2.46(.049)$ & $2.32(.061)$ & \\
Soda Ban & $2.84(.055)$ & $2.55(.074)$ & $\mathrm{P}<.01$ \\
City Smoking Ban & $2.64(.058)$ & $2.09(.073)$ & $\mathrm{P}<.01$ \\
Car Smoking Ban & $2.33(.052)$ & $1.83(.062)$ & $\mathrm{P}<.01$ \\
Annual Physical & $1.89(.038)$ & $1.87(.050)$ & \\
Train Parents & $1.81(.036)$ & $1.82(.048)$ & \\
Educate Students & $2.19(.040)$ & $1.99(.052)$ & $\mathrm{P}<.01$ \\
Eliminate Risky Sports & $5.42(.051)$ & $4.45(.084)$ & $\mathrm{P}<.01$ \\
\hline
\end{tabular}

This finding somewhat conflicts with others, such as that of Laurie Beck and colleagues, who found that racial differences in law compliance for a given public health law intervention were less than expected-even nonsignificant-between certain groups. ${ }^{159}$ It is possible that gaps in general support for a law do not actually influence individual-behavioral modification, or it is also possible that the data presented for this Article is consistent with a widespread general gap across ethnic groups for both support and adoption of interventions. For example, Morain and Mello found that African-Americans and Latinos were more supportive of various new-frontier public health law interventions, and that these differences had a large and significant effect size. ${ }^{160}$ Further research is needed to clarify these uncertainties. Because public health law interventions target a wide and diverse audience to reach the same broad public health goal, it is worth considering whether this one-size-fits-all messaging makes sense. It is troubling that groups most sympathetic to the intervention are also those least likely to be positively impacted by it. ${ }^{161}$ Put differently, while members of minority groups support a variety of nudges, evidence suggests that within these public health domains, these groups are overrepresented in negative public health outcomes (e.g.

159. See Laurie Beck et al., Associations Between Sociodemographics and Safety Belt Use in States with and Without Primary Enforcement Laws, 97 Ам. J. PuB. Health 1619, 1622 (2007).

160. Morain \& Mello, supra note 9, at 493.

161. Compare the results presented above, showing strong minority-group support for interventions, with the outcomes presented in James L. Pirkle et al., Trends in the Exposure of Nonsmokers in the U.S. Population to Secondhand Smoke: 1988-2002, 114 Envtl. Health Persp. $853,854-55$ (2006), which showed that people of color are disproportionately impacted by secondhand smoke despite prior public health interventions. 
smoking harms, food and diet harms, and sports injuries). This disconnect between support, expected behavioral changes, and public health outcomes for minority group members could be due to many reasons, but it may be that one core cause of this disparity is the failure to properly calibrate the messenger and the message to particular demographic constituencies. This failure may be because society has little to no prior knowledge about why particular sociodemographic groups respond positively or negatively to certain interventions. ${ }^{162}$

\section{B. Gender, Ideology, and Behavior-Identified Groups}

Some sociodemographic groups present divergent responses across almost all public health law intervention domains described in this Article. This is particularly true of differences between male and female respondents and the responses of conservatives versus moderate and liberal respondents, as shown in Tables 4 and 5.

Table 4. Proposed Interventions (Mean Responses by Gender)

\begin{tabular}{lccc}
\hline Proposed Intervention & $\begin{array}{c}\text { Male } \\
\text { Mean (S.E.) }\end{array}$ & $\begin{array}{c}\text { Female } \\
\text { Mean (S.E.) }\end{array}$ & $\begin{array}{c}\text { Mean } \\
\text { Difference }\end{array}$ \\
\hline Fast-Food Calories & $2.46(.049)$ & $1.91(.059)$ & $\mathrm{P}<.01$ \\
Sit-Down Calories & $2.60(.049)$ & $2.00(.059)$ & $\mathrm{P}<.01$ \\
Soda Ban & $2.93(.055)$ & $2.35(.072)$ & $\mathrm{P}<.01$ \\
City Smoking Ban & $2.60(.058)$ & $2.19(.076)$ & $\mathrm{P}<.01$ \\
Car Smoking Ban & $2.31(.052)$ & $1.86(.065)$ & $\mathrm{P}<.01$ \\
Annual Physical & $1.98(.038)$ & $1.67(.048)$ & $\mathrm{P}<.01$ \\
Train Parents & $1.93(.036)$ & $1.57(.047)$ & $\mathrm{P}<.01$ \\
Educate Students & $2.24(.040)$ & $1.89(.052)$ & $\mathrm{P}<.01$ \\
Eliminate Risky Sports & $5.16(.055)$ & $5.03(.079)$ & \\
\hline
\end{tabular}

162. See Morain \& Mello, supra note 9, at 494 (calling for those who are selling the efficacy of these interventions to "seek to understand the values held by different segments of the population and incorporate those values into policy decisions"). 
Table 5. Proposed Interventions

(Mean Responses by IdeOlogy)

\begin{tabular}{lccc}
\hline Proposed Intervention & $\begin{array}{c}\text { Conservative } \\
\text { Mean (S.E.) }\end{array}$ & $\begin{array}{c}\text { Moderate/Liberal } \\
\text { Mean (S.E.) }\end{array}$ & $\begin{array}{c}\text { Mean } \\
\text { Difference }\end{array}$ \\
\hline Fast-Food Calories & $2.91(.085)$ & $2.02(.040)$ & $\mathrm{P}<.01$ \\
Sit-Down Calories & $3.02(.084)$ & $2.15(.040)$ & $\mathrm{P}<.01$ \\
Soda Ban & $3.34(.089)$ & $2.49(.049)$ & $\mathrm{P}<.01$ \\
City Smoking Ban & $2.82(.093)$ & $2.32(.052)$ & $\mathrm{P}<.01$ \\
Car Smoking & $2.64(.088)$ & $1.97(.044)$ & $\mathrm{P}<.01$ \\
Annual Physical & $2.01(.063)$ & $1.83(.034)$ & $\mathrm{P}<.01$ \\
Train Parents & $2.08(.063)$ & $1.70(.030)$ & $\mathrm{P}<.01$ \\
Educate Students & $2.51(.068)$ & $1.97(.034)$ & $\mathrm{P}<.01$ \\
Eliminate Risky Sports & $5.78(.072)$ & $4.83(.055)$ & $\mathrm{P}<.01$ \\
\hline
\end{tabular}

The directional differences between both groups are as expected. ${ }^{163}$ On eight of the nine interventions (except football elimination) male respondents exhibited statistically significant lower support. For conservatives, the results are evidence of statistically significant lower support for all nine proposed public health law interventions.

Viewed through the lens of a political-psychological framework, the consistency of the conservative responses and the resistance to education are consistent with an affective decision-making heuristic-an instinctively political response to the public health intervention regardless of its potential or actual efficacy. ${ }^{164}$ For this sociodemographic group, there may be less balancing of the objective scientific evidence and more of an instinctive switch-flipping orientation toward policy, which would provide an initial range for how one feels about any intervention, separate from an evaluation of the actual costs and benefits of the intervention itself. ${ }^{165}$ One indicator of this affective disposition may be the resistance to a particular public health law intervention regardless of invasiveness, deterrence, or individual costs. If conservatives resist these interventions, notwithstanding all of these mediators, it may suggest a more direct affective evaluation of the interventions themselves. Therefore, particularly with respect to members of the sample who identify as conservative, opinions and

163. The differences described in this Article were evaluated in isolation using analysis of variance tools to measure group response differences across sociodemographic characteristics.

164. See generally Melissa L. Finucane et al., The Affect Heuristic in Judgments of Risks and Benefits, 13 J. Behav. Decision Making 1 (2000) (finding that instinctive affect-based responses to a stimulus influence individual judgment about the risks and benefits of specific hazards).

165. Id. See generally George F. Loewenstein et al., Risk as Feelings, 127 Psych. Bull. 267 (2001) (suggesting that a decision maker's immediate visceral reactions to risks and uncertainties in decison making may prevent them from engaging in a cost-benefit weighing of their choices). 
behaviors could be viewed as an emotional predisposition against all of these interventions based on a perceived or actual distance between these actions and one's individual political orientation. ${ }^{166}$ If so, this would serve as confirmation that, generally speaking, one's political psychology, if conservative, causes a drop in support for any public health intervention and a drop in expected compliance with the intervention's policy and law changes (such as ignoring calorie counts or other law-required information). This approach is consistent with the observations of others that conservatives, whose ideology is rooted in a mistrust of government's moral or legal authority beyond a limited sphere, may experience a psychological predisposition to oppose these policies, through both noncompliance with formal legal rules (for example, smoking in places forbidden by law) and by choosing to ignore behavior modifications rooted in information-based regimes (for example, ignoring calorie counts when evaluating food choices). ${ }^{167}$

Table 6. Proposed Interventions

(Mean Responses by Smoker-Status)

\begin{tabular}{lccc}
\hline Proposed Intervention & $\begin{array}{c}\text { Smoker } \\
\text { Mean (S.E.) }\end{array}$ & $\begin{array}{c}\text { Nonsmoker } \\
\text { Mean (S.E.) }\end{array}$ & $\begin{array}{c}\text { Mean } \\
\text { Difference }\end{array}$ \\
\hline Fast-Food Calories & $2.48(.103)$ & $2.25(.042)$ & $\mathrm{P}<.05$ \\
Sit-Down Calories & $2.59(.099)$ & $2.38(.042)$ & $\mathrm{P}<.05$ \\
Soda Ban & $3.00(.113)$ & $2.70(.048)$ & $\mathrm{P}<.01$ \\
City Smoking Ban & $4.16(.127)$ & $2.12(.045)$ & $\mathrm{P}<.01$ \\
Car Smoking Ban & $2.83(.119)$ & $2.04(.043)$ & $\mathrm{P}<.01$ \\
Annual Physical & $1.93(.076)$ & $1.88(.033)$ & \\
Train Parents & $1.83(.072)$ & $1.81(.031)$ & \\
Educate Students & $2.17(.079)$ & $2.12(.035)$ & \\
Eliminate Risky Sports & $5.16(.109)$ & $5.11(.049)$ & \\
\hline
\end{tabular}

166. The only other public opinion survey of a similar scope, Morain \& Mello, supra note 9, at 493, initially hypothesized that respondents' views on legitimacy might provide an alternative explanation-whether causal or correlational-with decisional variance across subgroups. Yet, concepts of trust in public health officials, perceptions of procedural fairness in public health decision making, and public perception of the quality of public health messenger's performance were not significantly associated with public support of a given public health law intervention.

167. See Margaret Levi et al., Conceptualizing Legitimacy, Measuring Legitimating Beliefs, 53 Am. Behav. Scientist 354 (2009) (describing the nexus between acceptance of legitimacy and adoption of beliefs); see also Richard A. Epstein, Let the Shoemaker Stick to His Last: A Defense of the "Old" Public Health, 46 Persp. Biological Med. (Special Issue) s138 (Supp. 2003). See William J. Novak, Private Wealth and Public Health: A Critique of Richard Epstein's Defense of the "Old" Public Health, 46 Persp. Biological Med. (Special Issue) s176 (Supp. 2003), for a response to the claims. 
In contrast, for example, Table 6 shows results for respondents who identify as smokers and have a more sophisticated form of policy-support differentiation. This works well within an identity-protective cognitive framework of the kind described by Kahan and colleagues as well as a political-psychological framework. As Kahan and Braman explain: "It's not comforting-indeed, it's psychically disabling-to entertain beliefs about what's harmless and what's harmful that force one to renounce commitments and affiliations essential to one's identity."168 Smokers reported differential (lower) levels of support for five of the nine proposed policies, all of which involved government regulation of smokers' conduct or governmental efforts to control content (soda) and the provision of calorie count information to the general public (education). Put differently, with respect to youth sports regimes, smokers' responses were indistinguishable from the general public. But, with regimes that either eliminated freedom of choice or required that choice be informed by additional information, smokers were less likely to support the proposed intervention. This suggests that smokers' policy-values may operate across more than one vector and may indeed include broad principled reasoning rooted in belief systems involving information, autonomy, choice, and risk. Further research is needed to test the strength of these connections. The reason may also be that laws blurring the line between a behavior (smoking) and status (smoker) may in fact cause health harms to those whose status or identity is disempowered by the law. ${ }^{169}$ But in truth, the "why" behind either consistent conservative rejection of these interventions or the more sophisticated form of smoker rejection may not matter as much as some scholars think.

This is because public health law advocates and scholars may have assumed that a given legal intervention, if properly communicated and supported by data about the potential effectiveness of its results, would result in widespread adoption by the general public. ${ }^{170}$ These advocates have reasonably postulated that "documenting the effectiveness" of these laws would not only help achieve compliance but

168. Dan M. Kahan \& Donald Braman, Cultural Cognition and Public Policy, 24 Yale L. \& Pol'y Rev. 149, 155 (2006).

169. For example, law and society scholars suggest that laws expanding opportunity or are inclusive of historically disempowered groups will lead to greater health outcomes as a result of decreasing the stress associated with membership in a group that laws discriminate against. See, e.g., Jason Schnittker \& Jane D. McLeod, The Social Psychology of Health Disparities, 31 AnN. Rev. Sociol. 75, 84-86 (2005); David M. Engel \& Frank W. Munger, Rights of Inclusion: Law and Identity in the Life Stories of Americans with Disabilities (2003).

170. See, e.g., Morain \& Mello, supra note 9, at 486-87. 
also encourage expansion of existing iterations of these laws. ${ }^{171}$ But, with respect to the individuals identifying themselves as conservative, the consistency across all policy choices, and the education question, suggests something more basic at work.

\section{Critiquing the Political-Psychological Approach}

The survey results present substantial barriers, empirically and otherwise, for those scholars and advocates across public health domains who believe that the transmission of law through general communication and the education and information content of these laws will actually result in changed individual behavior-different public health choices. Instead, while a variety of familiar sociodemographic variables are correlated with increased support or opposition to public health law interventions, the challenge of reaching or selling conservatives is greater than previously assumed.172 Thus, a political-psychological approach to the theory behind public health lawmaking and public health law communication is necessary, and it may be useful to first focus on the group with the most resistance (conservatives) because it has the most room for overall population impact on a raw number basis given the express resistance and the fact that this group is a significant portion of the overall U.S. population. ${ }^{173}$

But, other sociodemographic groups may also benefit from a targeted messaging approach. More research is needed to identify how and when these approaches would be most effective; however, as an initial matter, many public health marketing campaigns are already aligned and targeted to singular sociodemographic constituencies (i.e. those captured by Nielsen ratings), and thus, the sociodemographic data in its simplest form allows for a simple deployment of targeted campaigns along simple slices of these demographics. At present, these communications are still needed. Similarly, with respect to efforts to communicate more effectively, Kahan's 2014 vaccination

171. See Dinh-Zahr et al., supra note 7, at 50 (discussing the effectiveness of seatbelts).

172. For example, conservative ideology could be determinative of individual responses to nudge interventions in a way similar to the conflict between state actors and the federal government with respect to state resistance to ACA implementation. Elizabeth Weeks Leonard, Rhetorical Federalism: The Role of State Resistance in Health Care Decision Making, 39 J.L. MED. Eтнісs 73, 75 (2011) (identifying how a focus on "rhetorical federalism" could cause a juxtaposition between "political issues of individual rights and the role of government in health care").

173. But see Aaron Wildavsky, Choosing Preferences by Constructing Institutions: A Cultural Theory of Preference Formation, 81 AM. PoL. SCI. Rev. 3 (1987) (suggesting that ideology plays less of a role than described in this Article). 
study builds on these insights and leads toward a bold conclusion. ${ }^{174}$ For Kahan, more research about the scientific efficacy of certain public health initiatives is not the answer. Scholars should stop focusing energy on proving that a problem exists and that their solution-legal or otherwise-is the primary way to stop it. Instead, "[t]he most important [conclusion of recent research] is that the public health establishment play a more active leadership role in risk communication." ${ }^{175}$

\section{CONClusion}

To move the science of public health lawmaking forward, future research should place more emphasis on both the theoretical and empirical foundations of health policy, public opinion, and the internalization of legal norms. There is still much unknown about how and why individuals choose to reject or accept modern nudgebased public health law interventions and about the need for either a complex or simplified framework for this approach. Ideally, this new research would lead toward greater clarity about both support and internalization, which would then lead toward a new and more comprehensive framework focused on the communication of law to diverse sociodemographic groups in ways that best maximize the likelihood that these groups will support these interventions and adopt the desired behavior modification.

Further, data is needed that focuses on intersectional race, gender, sexual orientation, regional, and income differences in public opinion about public health law interventions, particularly given that core public health and medicine interventions have had cross-sectional impacts. ${ }^{176}$ For example, it may be possible that low-income AfricanAmerican women have significantly lower levels of support for these interventions, given this group's unique experiences with public health interventions over time. ${ }^{177}$ Similarly, the data presented in this Article, like many other large public opinion samples, was not analyzed for the unique opinions and experiences of lesbian, gay, bisexual, transgender, queer, intersexual, and asexual (LGBTQIA) respondents with respect to government authority and legal regimes ${ }^{178}$ because the

174. KAHAN, supra note 11 , at 4 .

175. Id.

176. See Nan D. Hunter, Rights Talk and Patient Subjectivity: The Role of Autonomy, Equality, and Participation Norms, 45 Wake Forest L. Rev. 1525, 1528-35 (2010) (discussing the impact of civil rights movements on informed consent).

177. See Michele Goodwin, Prosecuting the Womb, 76 Geo. Wash. L. Rev. 1657, 1657-66 (2008).

178. See, e.g., Nan D. Hunter, Civil Rights 3.0, in A Nation of Widening Opportunities? The Civil Rights Act at Fifty (Samuel Bagenstos \& Ellen Katz eds.) (forthcoming). 
survey panel from which respondents were drawn did not ask respondents for LGBTQIA self-identification. With respect to income and intersectionality, robust normative scholarship regarding the importance of income in determining the quality and provision of healthcare $^{179}$ can be bridged with further research about how and why some low-income, diverse populations may support public-health interventions at higher rates notwithstanding receiving what many perceive to be substandard care. With respect to the intersection of geography and the above factors, perhaps public opinion of these reforms reflects not only a traditional red-state, blue-state bias, but an urban-rural distinction within these states. ${ }^{180}$ Thus, further refinement of both survey panel recruitment methodologies and sociodemographic representation within these panels may yield further insights into the role that these differences play in the acceptance or rejection of public health law interventions. ${ }^{181}$ Finally, further research about the link between public opinion and adoption of public health nudges must extend beyond conventional U.S. samples to incorporate a larger sampling of opinions from individuals around the globe to determine whether the broad scale acceptance of public health law interventions in the United States extends to a variety of other populations and political regimes. ${ }^{182}$

Ultimately, what does this shift from coercion to nudging mean for public health outcomes and public health law research? With respect to outcomes, if the public initially resists these new interventions or doubts their efficacy, how can the public's health be substantially improved over time? With respect to research, other scholars of public health law research rightly define this problem as the "characteristic twenty-first-century public health law challenge: how to change ingrained, satisfying, normative, and profitable, behavior by manipulating the environment and nudging individuals." ${ }^{183}$ But, new public

179. See Frank Pasquale, Access to Medicine in an Era of Fractal Inequality, 19 AnNALS Health L. 269 (2010).

180. See Sidney D. Watson, Mending the Fabric of Small Town America: Health Reform \& Rural Economies, 113 W. VA. L. REV. 1 (2010).

181. It is fair to say that some of the political variance described here may be a national or regional artifact of the partisan alignments for these particular public health law interventions. A helpful reviewer identified that other public-health interventions may have a different partisan valence and may thus challenge assumptions present in this initial inquiry. Further research is needed to test these hypotheses.

182. See generally Patricia C. Kuszler, Global Health and the Human Rights Imperative, 2 Asian J. WTO \& Int'l Health L. \& Pol'y 99 (2007); Michelle Marie Mello et al., The Role of Law in Public Health: The Case of Family Planning in the Philippines, 63 Soc. ScI. \& Med. 384 (2006).

183. Scott Burris \& Evan Anderson, Legal Regulation of Health-Related Behavior: A HalfCentury of Public Health Law Research, 9 Ann. Rev. L. \& Soc. Scr. 95, 105 (2013). 
health law interventions, even those designed as nudges, may still encounter substantial public resistance-particularly from identifiable subsets of the body-politic. Therefore, for these interventions to have their intended impact, lawmakers and scholars must anticipate and devise ways to efficiently surmount that resistance by first understanding the differences in how populations perceive and respond to these laws.

The death of public health law intervention popularity (and the boogeyman of paternalism) may be somewhat exaggerated. Public support for public health law interventions is generally quite high, suggesting that further interventions, on a variety of matters, may receive a strong baseline of support. Yet, there remains a substantial gap between the policies that respondents want and the interventions they receive. Further, because of strong sociodemographic and political differences in responses to interventions, the efficacy of nudge-based interventions may ultimately depend on how much members of particular groups like the intervention and are encouraged to adopt and maintain it. Thus, going forward, more research is needed to increase the efficacy and efficiency of future nudge-based public health law interventions. 


\section{Appendix}

The survey was administered online using SurveyMonkey's online panel tool, a standing, probability-based, nationally representative sample of U.S. adults maintained by SurveyMonkey. SurveyMonkey's online panel members are recruited on a rolling basis and asked to participate in a variety of online surveys for SurveyMonkey's paid subscribers. Panel members are initially recruited through their utilization of SurveyMonkey's free-sampling tool, which is widely available and used by a cross sample of U.S. individuals and households. SurveyMonkey collects data on individual panel members' demographic characteristics, ranging from gender, race, and address, to political view, income, and education. For this survey, I requested a sampling frame of nationally representative members of ethnic minority groups. The final survey was fielded during July 2013, and SurveyMonkey provided a merged data file that included the responses and participant demographic information. I selected 2,500 respondents to receive the survey, and 2,043 completed the survey (a $81 \%$ participation rate). ${ }^{184}$ The survey was fielded over a period of several days and included a daily reminder. ${ }^{185}$ Of the survey respondents, $51.7 \%$ identified as married, $17.2 \%$ as smokers, $68 \%$ as male, and $69.3 \%$ as white. Further $37 \%$ of the sample identified as liberal, $30 \%$ identified as conservative, and the remainder identified as moderates. While these percentages are not fully representative of the national population, the statistical analyses performed herein still provide robust results when differentiating attitudes between various groups.

The data analysis described herein uses the raw unweighted results for some descriptions of trends. Further, when presenting data from questions with Likert scales, ${ }^{186}$ respondents were grouped into narrower categories than the full seven-point scale response provided (for example, support or nonsupport versus ranges of support). Finally, this Article focuses primarily on the demographic differences between groups to describe broad trends and explain the sociodemographic distinctions between group support. These variables included race,

184. See AAPOR Task Force, AAPOR Report on Online Panels 26 (2010) and InterNAtional Organization for Standardization, Standard 26362 (2009) for further discussion of the participation rate criteria.

185. No evidence of bias was found for those who did not participate in or complete the survey.

186. See generally I. Elaine Allen \& Christopher A. Seaman, Likert Scales and Data Analyses, Quality Progress, July 2007, at 64, 64 (2007) (providing an explanation of Likert scales). 
smoker status, political ideology, sex, and gender. ${ }^{187}$ Missing sociodemographic data were rare (1\% or less), which is a result of the panel-participation criteria that required the maintenance and collection of this information prior to participation. ${ }^{188}$

187. These are all self-identified, and future work may incorporate additional measures designed to identify more factors (LGBTQIA status) as well as metrics designed to further explore underlying ideological differences within self-identified ideological groups.

188. Naturally, there are many critiques of panel data, and those critiques shall not be repeated at length here. Certainly, the interpretation of these surveys should be contextualized against nonobservational and observational limitations, processing and dissemination constraints, selection bias, questionnaire wording, and reporting accuracy, among other things. But, specifically speaking, one qualification bears particular mention here-SurveyMonkey's online panel is a volunteer, opt-in panel incentivized for participation through a variety of available (and unavailable) metrics, and therefore, some survey metrics, such as response rates, have no comparable analogue in this space. 